\title{
The overwhelming role of soils in the global atmospheric hydrogen cycle
}

\author{
T. S. Rhee ${ }^{1,2}$, C. A. M. Brenninkmeijer ${ }^{1}$, and T. Röckmann ${ }^{3,4}$ \\ ${ }^{1}$ Max Planck Institute for Chemistry, Atmospheric Chemistry Division, Mainz, Germany \\ ${ }^{2}$ Korea Polar Research Institute, Ansan, Korea \\ ${ }^{3}$ Max Planck Institute for Nuclear Physics, Atmospheric Physics Division, Heidelberg, Germany \\ ${ }^{4}$ Institute for Marine and Atmospheric Research Utrecht, Utrecht University, Utrecht, The Netherlands
}

Received: 20 September 2005 - Published in Atmos. Chem. Phys. Discuss.: 2 November 2005

Revised: 13 March 2006 - Accepted: 14 March 2006 - Published: 19 May 2006

\begin{abstract}
The removal of molecular hydrogen $\left(\mathrm{H}_{2}\right)$ from the atmosphere is dominated by the uptake in soils. Notwithstanding, estimates of the magnitude of this important process on a global scale are highly uncertain. The CARIBIC aircraft observations of the seasonal variations of $\mathrm{H}_{2}$ and its $\mathrm{D} / \mathrm{H}$ isotopic ratio in the Northern Hemisphere allow an independent, better constrained estimate. We derive that $82 \%$ of the annual turnover of tropospheric $\mathrm{H}_{2}$ is due to soil uptake, equaling $88( \pm 11) \mathrm{Tg} \mathrm{a}^{-1}$, of which the Northern Hemisphere alone accounts for $62( \pm 10) \mathrm{Tg} \mathrm{a}^{-1}$. Our calculations further show that tropospheric $\mathrm{H}_{2}$ has a lifetime of only $1.4( \pm 0.2)$ years - significantly shorter than the recent estimate of $\sim 2$ years - which is expected to decrease in the future. In addition, our independent top-down approach, confined by the global and hemispheric sinks of $\mathrm{H}_{2}$, indicates $64( \pm 12) \mathrm{Tg} \mathrm{a}^{-1}$ emissions from various sources of volatile organic compounds by photochemical oxidation in the atmosphere. This estimate is as much as up to $60 \%$ larger than the previous estimates. This large airborne production of $\mathrm{H}_{2}$ helps to explain the fairly homogeneous distribution of $\mathrm{H}_{2}$ in the troposphere.
\end{abstract}

\section{Introduction}

Hydrogen $\left(\mathrm{H}_{2}\right)$ gas is considered to be a promising future energy carrier (Ogden, 1999; Turner, 2004) and pilot scale implementation is already taking place. Of concern is the potential global environmental impact accompanying a large scale use of $\mathrm{H}_{2}$, and clearly this has to be thoroughly assessed at an early stage. Recent modeling studies (Schultz et al., 2003; Tromp et al., 2003; Warwick et al., 2004) presume that

Correspondence to: T. S. Rhee

(rhee@kopri.re.kr) major changes in the atmospheric $\mathrm{H}_{2}$ budget may occur when hydrogen gas is used on a large scale because of unavoidable leakage into the atmosphere. These studies provide scenarios for the consequent impact on the chemistry of the atmosphere and ultimately global climate.

However, present knowledge of the atmospheric $\mathrm{H}_{2}$ budget is rather qualitative given the large uncertainties in most of the source and sink strength determinations (Table 1). Particularly the estimation of the soil sink, which dominates the budget, is most uncertain being based on a "bottom-up" approach. Such approach basically uses the up-scaling from local measurements to the global scale, which is prone to large errors. Furthermore, all previous estimates depend on the $\mathrm{H}_{2}$ deposition velocity applied and the effective soil area. The deposition velocities are widely spread from 0.003 to $0.14 \mathrm{~cm} \mathrm{~s}^{-1}$ (Conrad and Seiler, 1980; Conrad and Seiler, 1985; Liebl and Seiler, 1976; Schmidt et al., 1980) (equivalent to approximately $4.2-200 \mathrm{Tg} \mathrm{a}^{-1}$ providing the effective soil surface area of $1.04 \times 10^{8} \mathrm{~km}^{2}$ (Table 4)). These values have been used for the estimation of global soil sinks in numerous literature (Novelli et al., 1999 and references therein).

In contrast, we apply an independent "top-down" approach and include not only the atmospheric $\mathrm{H}_{2}$ mixing ratio, but also the stable isotope composition. Isotope analysis is extraordinarily useful for investigating the atmospheric $\mathrm{H}_{2}$ cycle, since the two sink processes, uptake by soils and photochemical oxidation by $\mathrm{OH}$, are both accompanied by substantial, but strongly differing kinetic isotope effects. Moreover, nearly all of the 5 identified sources of $\mathrm{H}_{2}$ have a strongly differing isotopic composition (Table 1 ). The $\mathrm{D} / \mathrm{H}$ isotope ratio is commonly expressed as $\delta \mathrm{D}$ which is defined as $\delta \mathrm{D}=\left(\mathrm{R}_{\mathrm{SPL}} / \mathrm{R}_{\mathrm{SMOW}}-1\right) \times 1000(\%)$, where $\mathrm{R}_{\mathrm{SPL}}$ is the $\mathrm{D} / \mathrm{H}$ ratio of sample and $\mathrm{R}_{\text {SMOw }}$ is that of Standard Mean Ocean Water (SMOW) $(=0.015576 \pm 0.000006$; Hagemann et

Published by Copernicus GmbH on behalf of the European Geosciences Union. 
Table 1. The global budget of atmospheric $\mathrm{H}_{2}\left(\mathrm{Tg} \mathrm{a}{ }^{-1}\right)$. Isotopic signatures of sources are shown under the column, $\delta \mathrm{D}_{i}$. For the sink processes, the isotopic fractionation factors are shown as, $\alpha_{j}$, which is dimensionless. NH and SH stand for the Northern and Southern Hemisphere, respectively.

\begin{tabular}{|c|c|c|c|c|c|c|}
\hline & & \multirow[t]{2}{*}{ NH fraction } & \multirow{2}{*}{$\begin{array}{l}\text { Novelli et al. (1999) } \\
\text { Global }\end{array}$} & \multicolumn{3}{|c|}{ This study } \\
\hline & & & & Global & NH & SH \\
\hline Sources & $\delta \mathrm{D}_{i}(\%)$ & $\chi_{i}$ & & & & \\
\hline Fossil fuel combustion & $-270^{\mathrm{a}}$ & 0.9 & $15 \pm 10$ & $15 \pm 6$ & 13 & 1.5 \\
\hline Biomass burning & -90 & 0.53 & $16 \pm 5$ & $16 \pm 3$ & 8.4 & 7.5 \\
\hline Photochemical production & $190^{\mathrm{b}}$ & 0.65 & $40 \pm 16$ & $64 \pm 12$ & 42 & 23 \\
\hline Biogenic $\mathrm{N}_{2}$ fixation & $-700^{\mathrm{c}}$ & 0.6 & $3 \pm 1$ & $6 \pm 5$ & 3.6 & 2.4 \\
\hline Oceans & $-700^{c}$ & 0.4 & $3 \pm 2$ & $6 \pm 5$ & 2.4 & 3.6 \\
\hline Total sources & & & $77 \pm 16$ & $107 \pm 15$ & 69 & 38 \\
\hline Sinks & $\alpha_{j}$ & $\chi_{j}$ & & & & \\
\hline $\mathrm{OH}$ oxidation & $0.58 \pm 0.07^{\mathrm{d}}$ & 0.49 & $19 \pm 5$ & $19 \pm 3$ & 9.4 & 9.7 \\
\hline Soil uptake & $0.943 \pm 0.007^{\mathrm{e}}$ & 0.71 & $56 \pm 41$ & $88 \pm 11$ & 62 & 26 \\
\hline \multirow[t]{2}{*}{ Total sinks } & & & $75 \pm 41$ & $107 \pm 11$ & 72 & 35 \\
\hline & & & & $\delta \mathrm{D}_{\mathrm{QG}}$ & $\delta \mathrm{D}_{\mathrm{QN}}$ & $\delta \mathrm{D}_{\mathrm{QS}}$ \\
\hline Isotopic ratios of combined sources $(\% o)$ & & & & -7.2 & -2.6 & -16 \\
\hline Lifetime (years) & & & 2.1 & $1.4 \pm 0.2$ & & \\
\hline
\end{tabular}

${ }^{a}$ Rahn et al. (2002b); ${ }^{b}$ Rhee et al. (2006) ${ }^{1} ;{ }^{c}$ Rahn et al. (2003); ${ }^{d}$ Talukdar et al. (1996) at $277 \mathrm{~K} ;{ }^{e}$ average from Gerst and Quay (2001) and Rahn et al. (2002a)

${ }^{1}$ Rhee, T. S., Brenninkmeijer, C. A. M., Braß, M., and Brühl, Ch.: The isotopic composition of $\mathrm{H}_{2}$ from $\mathrm{CH}_{4}$ oxidation in the stratosphere and the troposphere, J. Geophys. Res., in review, 2006.

al., 1970).

The previous measurements of the $\delta \mathrm{D}$ value of atmospheric $\mathrm{H}_{2}$ were limited to the planetary boundary layer in contact with soils (e.g. Friedman and Scholz, 1974; Gerst and Quay, 2000). Since the soil surface destroys a major portion of atmospheric $\mathrm{H}_{2}$, this may lead to a large variability in $\delta \mathrm{D}$ values. In addition, other local sources may prevent the observation from being representative on synoptic scale of space. We analyzed the free tropospheric air samples collected by the CARIBIC project (Civil Aircraft for the Regular Investigation of the atmosphere Based on an Instrumented Container) (Brenninkmeijer et al., 1999). Being above the planetary boundary layer, the free troposphere represents "background" chemical composition of the troposphere. In addition, as indicated by the large vertical eddy diffusivity, the atmospheric mixing in the free troposphere is rapid so as to reduce a potential local bias. This provides us an unprecedented opportunity to apply the aircraft observations to the global atmospheric $\mathrm{H}_{2}$ cycle in the troposphere.

\section{Methods}

Air samples were collected over Europe and Africa at altitudes of 9 to $12 \mathrm{~km}$ using the CARIBIC Boeing 767. Two flights were carried out from Windhoek, Namibia, in May and July, and one flight from Cape Town, South Africa, in December, to Munich, Germany, all in 2000. The flight tracks cover $\sim 30^{\circ} \mathrm{S}$ to $\sim 50^{\circ} \mathrm{N}$ along the longitude $\sim 10^{\circ} \mathrm{E}$ (Table 2). Twelve air samples were regularly collected along the flight track in $21 \mathrm{~L}$ stainless steel tanks at a final pressure of 17 bar taking $\sim 20 \mathrm{~min}(\sim 300 \mathrm{~km}$ distance) per sample (Brenninkmeijer et al., 1999). Upon return of the aircraft aliquots were transferred into $2.5 \mathrm{~L}$ electro-polished stainless steel canisters at $5 \mathrm{bar}$, archived in a freezer at $-25^{\circ} \mathrm{C}$ for $2-3$ years, and used to determine the $\delta \mathrm{D}$ values and mixing ratios of $\mathrm{H}_{2}$ using a continuous-flow isotope ratio mass spectrometry (CF-IRMS) following the procedure described in detail by Rhee et al. (2004).

\section{Results}

Figure 1 shows the $\mathrm{H}_{2}$ mixing ratios and $\delta \mathrm{D}$ values along the 3 flight tracks together with in situ measurements of the ultrafine particle number concentrations for the size of $4-12 \mathrm{~nm}$ $\left(\mathrm{N}_{4-12}\right)$ (Heintzenberg et al., 2003), and the $\mathrm{CO}$ and $\mathrm{O}_{3}$ mixing ratios (Zahn et al., 2002). These in situ observations are utilized to define three characteristic regions. Large $\mathrm{N}_{4-12}$ indicates the uplifting of air parcels from the boundary layer 
Table 2. Logistic information on the air samples, their $\mathrm{H}_{2}$ and $\mathrm{CO}$ mixing ratios, and $\delta \mathrm{D}$ values.

\begin{tabular}{|c|c|c|c|c|c|c|c|c|c|}
\hline \multirow[t]{2}{*}{ Sample ID } & \multirow[t]{2}{*}{ Date } & \multirow[t]{2}{*}{ Lon. $\left({ }^{\circ} \mathrm{E}\right)$} & \multirow[t]{2}{*}{ Lat. $\left({ }^{\circ} \mathrm{N}\right)^{\S}$} & \multicolumn{2}{|c|}{$\left[\mathrm{H}_{2}\right](\mathrm{ppb})^{*}$} & \multicolumn{2}{|c|}{$\delta \mathrm{D}(\% o)^{*}$} & \multirow[t]{2}{*}{ No. of replicate } & \multirow[t]{2}{*}[\mathrm{CO}]{$(\mathrm{ppb})^{\mathbb{I}}$} \\
\hline & & & & Mean & $\mathrm{sd}$ & Mean & $\mathrm{sd}$ & & \\
\hline WAS-22-1 & 05/19/2000 & 15.43 & -15.81 & 528 & 2 & 139 & 3 & 3 & 76 \\
\hline WAS-22-2 & 05/19/2000 & 13.72 & -9.98 & 550 & 1 & 129 & 4 & 2 & 95 \\
\hline WAS-22-3 & 05/19/2000 & 11.66 & -4.57 & 545 & 3 & 139 & 3 & 1 & 82 \\
\hline WAS-22-4 & 05/19/2000 & 9.84 & 0.70 & 524 & 3 & 141 & 3 & 1 & 106 \\
\hline WAS-22-5 & 05/19/2000 & 9.33 & 6.31 & 552 & 0.1 & 125 & 3 & 2 & 126 \\
\hline WAS-22-6 & 05/19/2000 & 8.54 & 12.40 & 552 & 3 & 127 & 3 & 1 & 116 \\
\hline WAS-22-7 & 05/19/2000 & 7.95 & 18.29 & 557 & 3 & 126 & 3 & 1 & 91 \\
\hline WAS-22-8 & 05/19/2000 & 7.37 & 23.95 & 562 & 3 & 122 & 3 & 2 & 108 \\
\hline WAS-22-9 & 05/19/2000 & 6.86 & 29.43 & 557 & 3 & 125 & 3 & 1 & 98 \\
\hline WAS-22-10 & 05/19/2000 & 6.72 & 34.97 & 558 & 0.3 & 129 & 2 & 2 & 75 \\
\hline WAS-22-11 & 05/19/2000 & 7.67 & 40.82 & 558 & 3 & 129 & 3 & 1 & 89 \\
\hline WAS-22-12 & 05/19/2000 & 10.55 & 46.18 & 557 & 3 & 122 & 3 & 1 & 87 \\
\hline WAS-25-1 & $07 / 28 / 2000$ & 15.68 & -16.96 & 524 & 3 & 131 & 3 & 1 & 97 \\
\hline WAS-25-2 & $07 / 28 / 2000$ & 14.18 & -11.92 & 543 & 4 & 131 & 5 & 3 & 74 \\
\hline WAS-25-3 & $07 / 28 / 2000$ & 12.46 & -6.85 & 538 & 9 & 133 & 1 & 2 & 76 \\
\hline WAS-25-4 & $07 / 28 / 2000$ & 10.33 & -1.70 & 523 & 1 & 126 & 0.4 & 2 & 154 \\
\hline WAS-25-5 & $07 / 28 / 2000$ & 9.66 & 3.71 & 525 & 3 & 125 & 3 & 1 & 150 \\
\hline WAS-25-6 & $07 / 28 / 2000$ & 8.93 & 9.42 & 545 & 0.1 & 125 & 8 & 2 & 114 \\
\hline WAS-25-7 & $07 / 28 / 2000$ & 8.22 & 15.29 & 534 & 3 & 129 & 3 & 1 & 93 \\
\hline WAS-25-8 & $07 / 28 / 2000$ & 7.67 & 21.27 & 539 & 3 & 128 & 3 & 1 & 85 \\
\hline WAS-25-9 & $07 / 28 / 2000$ & 7.00 & 27.16 & 544 & 3 & 125 & 3 & 1 & 84 \\
\hline WAS-25-10 & $07 / 28 / 2000$ & 6.80 & 32.89 & 538 & 3 & 129 & 3 & 1 & 80 \\
\hline WAS-25-12 & $07 / 28 / 2000$ & 9.36 & 44.09 & 544 & 3 & 129 & 3 & 1 & 66 \\
\hline WAS 30-1 & $12 / 03 / 2000$ & 18.37 & -27.74 & 550 & 3 & 138 & 3 & 1 & 65 \\
\hline WAS 30-2 & $12 / 03 / 2000$ & 17.44 & -22.70 & 544 & 3 & 136 & 3 & 1 & 90 \\
\hline WAS 30-3 & $12 / 03 / 2000$ & 15.89 & -17.71 & 543 & 3 & 138 & 3 & 1 & 96 \\
\hline WAS 30-4 & $12 / 03 / 2000$ & 14.38 & -12.61 & 538 & 3 & 137 & 3 & 1 & 99 \\
\hline WAS 30-5 & $12 / 03 / 2000$ & 12.75 & -7.56 & 533 & 3 & 135 & 3 & 1 & 110 \\
\hline WAS 30-6 & $12 / 03 / 2000$ & 10.71 & -2.61 & 545 & 3 & 137 & 3 & 1 & 90 \\
\hline WAS 30-7 & $12 / 03 / 2000$ & 9.65 & 2.77 & 530 & 3 & 129 & 3 & 1 & 141 \\
\hline WAS 30-8 & $12 / 03 / 2000$ & 9.03 & 8.72 & 528 & 3 & 133 & 3 & 1 & 97 \\
\hline WAS 30-9 & $12 / 03 / 2000$ & 8.28 & 14.67 & 534 & 3 & 132 & 3 & 1 & 95 \\
\hline WAS 30-10 & $12 / 03 / 2000$ & 7.76 & 20.46 & 533 & 5 & 129 & 2 & 2 & 93 \\
\hline WAS 30-11 & $12 / 03 / 2000$ & 7.12 & 26.04 & 533 & 3 & 133 & 3 & 1 & 77 \\
\hline WAS 30-12 & $12 / 03 / 2000$ & 6.84 & 31.41 & 517 & 3 & 135 & 3 & 1 & 83 \\
\hline
\end{tabular}

$\S$ Negative values indicate the Southern Hemisphere.

* Uncertainties in the $\mathrm{H}_{2}$ mixing ratio and $\delta \mathrm{D}$ for single measurement are assumed to be the mean of the uncertainties of the replicate measurements. sd designates 1 standard deviation of the mean.

If Mean CO mixing ratios of the in situ measurements during whole air sampling period.

by deep convection near the intertropical convergence zone (ITCZ) (Heintzenberg et al., 2003). Simultaneous enhancement of $\mathrm{CO}$ confirms the occurrence of uplift of polluted boundary layer air to the cruising altitude. This region is defined as the equatorial tropics. The adjacent regions to the south and north are classified as representative for the Southern Hemisphere (SH) and the Northern Hemisphere (NH), respectively. Whereas the $\mathrm{SH}$ sections for each of the 3 flights lie entirely in the troposphere, the $\mathrm{NH}$ sections extend to near the tropopause or into the lowermost stratosphere where $\mathrm{O}_{3}$ mixing ratios are strongly elevated. These data are excluded from the present analysis as we focus on the $\mathrm{H}_{2}$ cycle in the troposphere. The flight segments assigned to the $\mathrm{NH}$ and $\mathrm{SH}$, respectively, are indicated in Fig. 1.

Following the partitioning of the flight tracks based on the in situ observations, we estimate the mean $\mathrm{H}_{2}$ mixing ratios and $\delta \mathrm{D}$ in the $\mathrm{SH}$ and $\mathrm{NH}$ sections of each flight. For this calculation we exclude one sample collected at $46^{\circ} \mathrm{N}$ in May, and one at $31 \circ \mathrm{N}$ in December. These two samples do not represent free tropospheric air masses, as they had 

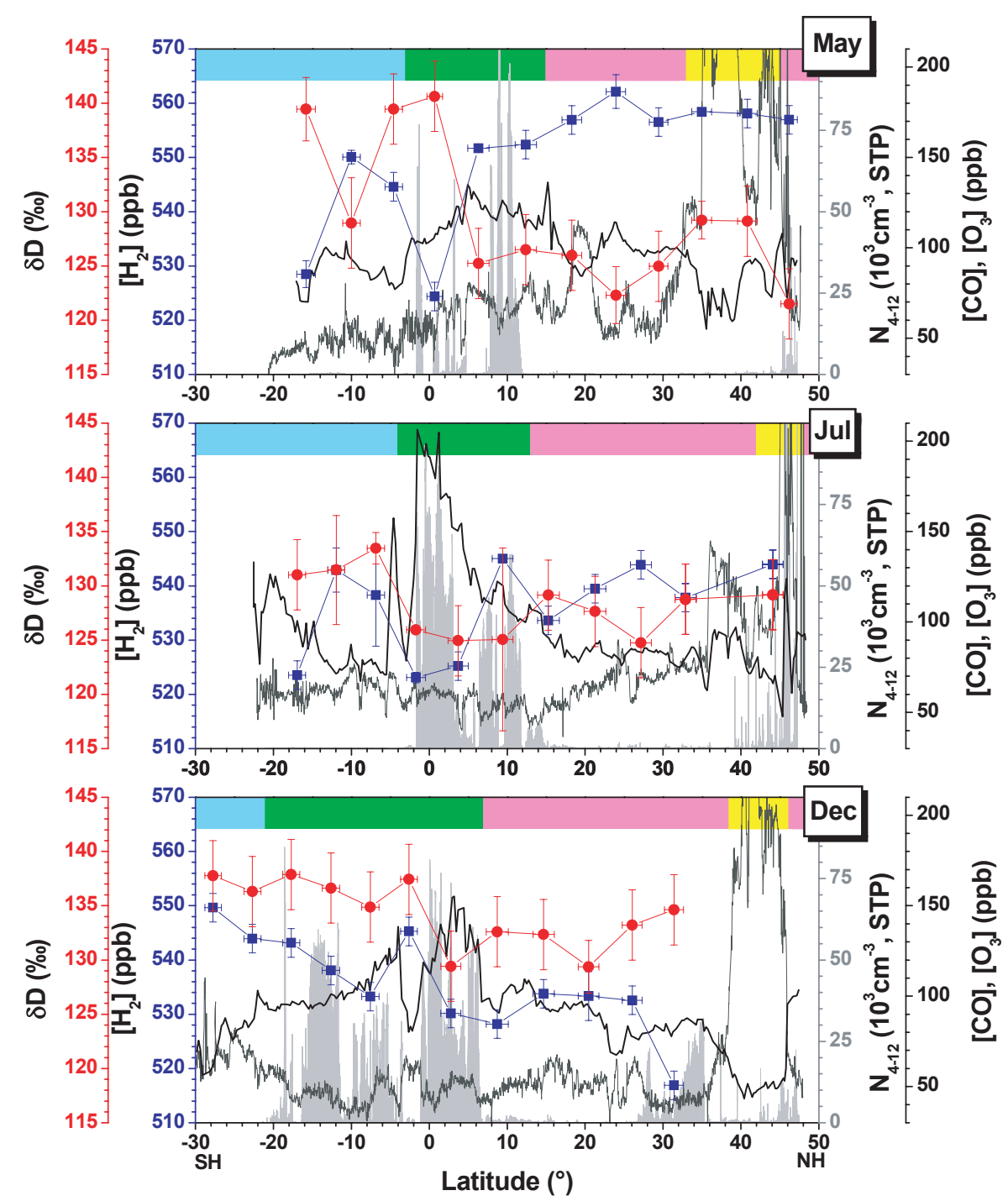

Fig. 1. The measured spatial variability of the mixing ratios of $\mathrm{H}_{2}$ (blue squares) and its $\delta \mathrm{D}$ values (red circles) in May, July, and December. The horizontal bars indicate the sampling distance and the vertical bars represent the analytical uncertainty $(1 \sigma)$. Furthermore the in situ observations of ultra-fine aerosol $\left(\mathrm{N}_{4-12}\right)$ (shaded areas), $\mathrm{CO}$ (thick line) and $\mathrm{O}_{3}$ (thin line) are shown. Color codes on top of each panel: cyan (Southern Hemisphere), green (equatorial tropics), and magenta (Northern Hemisphere), and yellow (the lowermost stratosphere).

resided at the surface prior to sampling. This is evidenced by the increase of $\mathrm{N}_{4-12}$ and the respective 5-day backward trajectories (see the web site www.knmi.nl/samenw/ campaign_support/CARIBIC/, together with other meteorological graphs for the flights). The $\mathrm{H}_{2}$ mixing ratios for the NH and SH (Figs. 2a and b) show almost the same seasonal cycle as observed at Mauna Loa (MLO) and Cape Grim (CGO) by the National Oceanic and Atmospheric Administration's Climate Monitoring and Diagnostics Laboratory (NOAA/CMDL) from 1989 to 1998 (Novelli et al., 1999). The observations at these two stations represent the background $\mathrm{H}_{2}$ variations in both hemispheres without local influences. The agreement in both phase and magnitude of the seasonal cycle of $\mathrm{H}_{2}$ mixing ratios confirms spatial homo- geneity of $\mathrm{H}_{2}$ in remote areas of the two hemispheres. Interestingly, additional evidence for this presented in Figs. 2a and $b$ clearly shows that the seasonality as observed at the two background stations closely abide the hemispheric mean values of $\mathrm{H}_{2}$ in the year 2000 (Novelli, personal communication).

The phase of the seasonal cycle of $\delta \mathrm{D}$ with respect to that for $\mathrm{H}_{2}$ shows a strong contrast between the two hemispheres (Figs. $2 \mathrm{c}$ and d). In the $\mathrm{NH}, \delta \mathrm{D}$ and $\mathrm{H}_{2}$ vary out of phase, while in the $\mathrm{SH}$ they are almost in phase. Moreover, although the amplitude of the $\mathrm{H}_{2}$ cycle in the $\mathrm{NH}$ is more than twice as large as that in the $\mathrm{SH}$, the amplitudes of the $\delta \mathrm{D}$ cycles are the same. In addition, while the annual mean $\mathrm{H}_{2}$ mixing ratios in both hemispheres are the same, the annual mean $\delta \mathrm{D}$ 

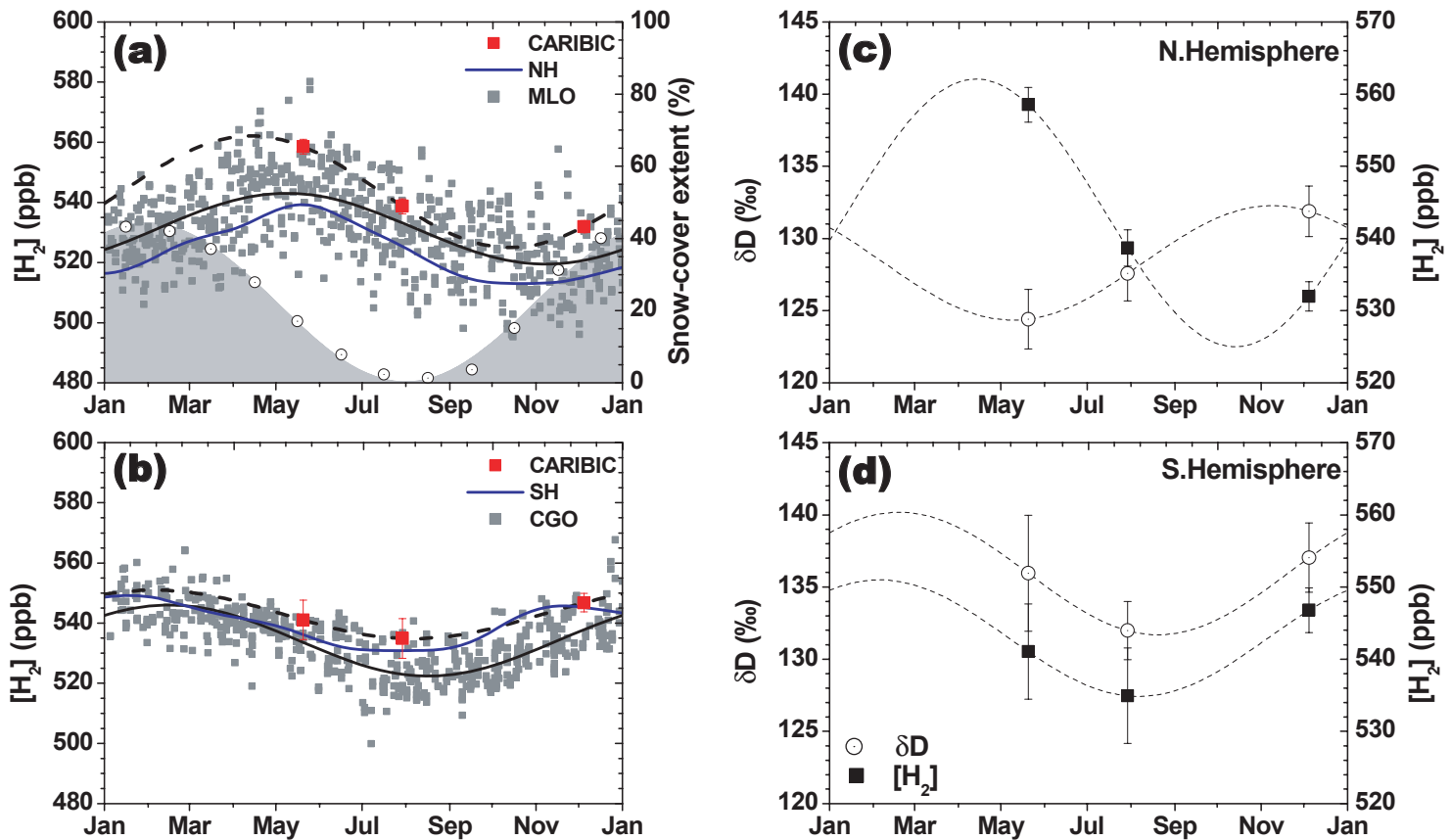

Fig. 2. Seasonal variations of the $\mathrm{H}_{2}$ mixing ratios and the $\delta \mathrm{D}$ values. (a and b) Comparison of the $\mathrm{H}_{2}$ mixing ratios between the airborne observations (CARIBIC) and the surface observations (NOAA/CMDL) (Novelli et al., 1999). MLO and CGO indicate the monitoring stations of Mauna Loa and Cape Grim. Dashed and solid lines are sinusoidal fits to the CARIBIC and NOAA/CMDL data sets, respectively. Blue lines indicate the hemispheric mean values of $\mathrm{H}_{2}$ for the year 2000 (P. Novelli, personal communication). In (a), the fraction of snowcover extent from NOAA satellite observations (Armstrong and Brodzik, 2001) in the Northern Hemisphere is reproduced with gray shading (sinusoidal fit) and dotted circles (mean monthly data for 20 year observations). (c and d) Seasonal variations of the $\delta \mathrm{D}$ values and the $\mathrm{H}_{2}$ mixing ratios in the Northern and Southern Hemisphere. The error bars represent 1 standard deviation of the mean.

value in the $\mathrm{SH}$ is $8 \%$ o higher (Table 3). These properties of the seasonal cycles of $\mathrm{H}_{2}$ and $\delta \mathrm{D}$ imply differences in the processes that control $\mathrm{H}_{2}$ in each hemisphere.

\section{Discussion}

\subsection{Northern hemispheric $\mathrm{H}_{2}$ cycle}

The spring time peak in the $\mathrm{H}_{2}$ mixing ratio and corresponding lowest $\delta \mathrm{D}$ value in the $\mathrm{NH}$ can be ascribed to the winter time accumulation of $\mathrm{H}_{2}$ emitted from sources with low $\delta \mathrm{D}$ values, while in fall these two parameters undergo opposite changes due to the strong uptake by soil during summer and the associated isotopic fractionation which renders the remaining $\mathrm{H}_{2}$ isotopically heavier. It has been long recognized that soil provides the most significant sink of atmospheric $\mathrm{H}_{2}$ (Liebl and Seiler, 1976). Long-term monitoring of $\mathrm{H}_{2}$ at different latitudes has revealed that the seasonal amplitude of $\mathrm{H}_{2}$ increases with latitude in the $\mathrm{NH}$ (Novelli et al., 1999) likely due to increase of the fraction of land area. Several factors such as soil temperature, humidity, and the organic carbon content are likely to influence the uptake rate (Conrad and Seiler, 1985). However, it is unclear how significantly these factors contribute to the soil uptake rate on
Table 3. Fitting parameters for $\mathrm{H}_{2}$ and $\delta \mathrm{D}$ representing their seasonal variations in the Northern $(\mathrm{NH})$ and Southern Hemisphere $(\mathrm{SH}) . \mathrm{H}_{2}$ mixing ratios and $\delta \mathrm{D}$ values in both hemispheres are fitted to a function, $y=a \cos (2 \pi(x-\phi))+m$.

\begin{tabular}{lcccc}
\hline & \multicolumn{2}{c}{$\left[\mathrm{H}_{2}\right](\mathrm{ppb})$} & \multicolumn{2}{c}{$\delta \mathrm{D}(\%)$} \\
\hline & $\mathrm{NH}$ & $\mathrm{SH}$ & $\mathrm{NH}$ & $\mathrm{SH}$ \\
\hline Amplitude $(a)$ & $18.2 \pm 1.6$ & $8.1 \pm 3.2$ & $4.0 \pm 0.9$ & $4.2 \pm 1.6$ \\
Phase* $(\phi)$ & $0.28 \pm 0.01$ & $0.10 \pm 0.07$ & $0.85 \pm 0.05$ & $0.13 \pm 0.06$ \\
Average $(m)$ & $543.4 \pm 0.8$ & $542.9 \pm 1.8$ & $128.3 \pm 0.7$ & $135.9 \pm 1.1$ \\
\hline
\end{tabular}

*Units for phase are year.

a global scale and which factor controls the seasonal variation of soil uptake as none of the literature clearly shows a correlation between a given parameter and soil deposition velocity of $\mathrm{H}_{2}$. Probably a complex non-linear combination of factors that control $\mathrm{H}_{2}$ uptake by soil in a local environment (e.g. Yonemura et al., 2000a) makes it difficult to find a major driving force on the global scale.

Long-term satellite observations show a large annual oscillation of the snow-cover extent by as much as $\sim 40 \%$ of the 
NH land area (Armstrong and Brodzik, 2001) (see Fig. 2a). A snow-cover on the soil surface hinders contact with air and retards diffusion of $\mathrm{H}_{2}$ into soil voids where $\mathrm{H}_{2}$ removal takes place (Yonemura et al., 2000b). Microbial or enzymatic activity of $\mathrm{H}_{2}$ consumption also decreases with soil temperature. Furthermore, the phase of seasonal variation of snow-cover extent corresponds precisely to the $\mathrm{NH} \mathrm{H}_{2}$ cycle: the fastest removal rate of $\mathrm{H}_{2}$ in late July coincides with the lowest snow-cover extent, and vice versa. Therefore, we hypothesize that the large seasonal cycle of the snow-cover extent dominates the seasonality of $\mathrm{NH} \mathrm{H}_{2}$ and should be a key indicator for the $\mathrm{H}_{2}$ uptake rate by soils.

Continued global warming will increase the sink strength of soils on the basis of a positive correlation with soil temperature (Yonemura et al., 2000b). Moreover the expected shrinking of permafrost and annual snow-cover over the $\mathrm{NH}$ (Armstrong and Brodzik, 2001; Folland et al., 2001), both of which are associated with the global warming, will further enhance the soil sink in future.

\subsection{Soil uptake rate of atmospheric $\mathrm{H}_{2}$}

When the isotopic compositions of the sources are invariable, the relative change in the $\delta \mathrm{D}$ value compared to that in the $\mathrm{H}_{2}$ mixing ratio depends solely on sink processes at equilibrium state of the isotopic ratio between source and sink processes in a reservoir, and is represented by isotopic fractionation factor (Lassey et al., 2000). One can calculate the isotopic fractionation factor $(\alpha)$ at the isotopic equilibrium by virtue of the Rayleigh distillation model (Allan et al., 2001; Bergamaschi et al., 2000) and verify the isotopic equilibrium based on the relation $\alpha=\frac{R_{Q}}{R_{r}}$, where $R_{Q}$ is the isotopic ratio of the combined sources and $R_{r}$ is that for the reservoir. Since we are interested in the annual atmospheric $\mathrm{H}_{2}$ cycle, we assume isotopic equilibrium at a timescale of typically one year. Accordingly, an isotopic mass balance is met on an annual basis and seasonal variations of source emissions do not necessarily influence the determination of isotopic fractionation factor (Appendix A). As is shown in Sect. 4.6, the $\mathrm{NH} \mathrm{H}_{2}$ cycle in the year 2000 was indeed at isotopic equilibrium. Influences of varying characteristic isotopic ratio of sources and of the inter-hemispheric exchange of air to the determination of $\alpha$ are discussed in Sect. 4.3.

Atmospheric $\mathrm{H}_{2}$ is destroyed not only by soil uptake, but the oxidation of $\mathrm{H}_{2}$ by the $\mathrm{OH}$ radical also contributes to the removal of $\mathrm{H}_{2}$. This process induces a strong isotopic fractionation (Talukdar et al., 1996), thus efficiently increasing $\delta \mathrm{D}$ of the atmospheric $\mathrm{H}_{2}$ reservoir. These two loss processes and their associated isotopic fractionation provide a key to derive the magnitude of the $\mathrm{H}_{2}$ uptake by soil. The apparent isotopic fractionation factor $\left(\alpha_{\mathrm{app}}\right)$ of $0.90( \pm 0.02)$, which reflects the combined sink processes, is derived by ap- plying the Rayleigh distillation model (Rayleigh, 1902):

$\alpha_{\text {app }}=1+\frac{\ln \frac{\left(\delta \mathrm{D}_{m x} \times 10^{-3}+1\right)}{\left(\delta \mathrm{D}_{m n} \times 10^{-3}+1\right)}}{\ln \frac{\left[\mathrm{H}_{2}\right]_{m n}}{\left[\mathrm{H}_{2}\right]_{m x}}}$

where indices of $m n$ and $m x$ indicate the minimum and maximum values for annual cycle of $\delta \mathrm{D}$ and $\mathrm{H}_{2}$ shown in Fig. 2c. The uncertainty of $\alpha_{\text {app }}$ is derived by error propagation in (1) using the uncertainties of the sinusoidal fittings for $\delta \mathrm{D}$ and $\mathrm{H}_{2}$ (Table 3). A boot strap method (Press et al., 1992) is applied to estimate uncertainties of the fitting parameters within the errors of data. One thousand results that fit the annual sinusoidal cycle were collected to estimate uncertainty.

The calculated value implies that the $\mathrm{NH}$ soil sink accounts for $87( \pm 7) \%$ of the total NH sink since the fraction of soil uptake $(g)$ can be derived by $\alpha_{\text {app }}=g \times \alpha_{\text {soil }}+(1-g) \times \alpha_{\mathrm{OH}}$, where the isotopic fractionation factor for the photochemical oxidation with $\mathrm{OH}\left(\alpha_{\mathrm{OH}}\right)$ is $0.58( \pm 0.07)$ (Talukdar et al., 1996) at an average tropospheric temperature of $277 \mathrm{~K}$ (Prather and Spivakovsky, 1990) and for soil uptake $\left(\alpha_{\text {soil }}\right)$ is 0.943( \pm 0.007$)$ (Gerst and Quay, 2001; Rahn et al., 2002a). Next we determine the absolute soil sink strength in the $\mathrm{NH}$ using the amount of $\mathrm{H}_{2}$ that is oxidized by reaction with $\mathrm{OH}$ in the troposphere. This amount is calculated given the known reaction rate constant (DeMore et al., 1997) at an average tropospheric temperature of $277 \mathrm{~K}$ $\left(=4.52( \pm 0.516) \times 10^{-16} \mathrm{~cm}^{3}\right.$ molecule $\left.{ }^{-1} \mathrm{~s}^{-1}\right)$, an $\mathrm{OH}$ concentration of $9.7( \pm 0.6) \times 10^{5}$ molecules $\mathrm{cm}^{-3}$ (Prinn et al., 1995), a global tropospheric $\mathrm{H}_{2}$ burden of $155( \pm 2) \mathrm{Tg}$ (Novelli et al., 1999), and the ratio of $\mathrm{H}_{2}$ burdens in the $\mathrm{NH}$ to $\mathrm{SH}$ of 0.97 (Novelli et al., 1999). This results in the $\mathrm{H}_{2}$ oxidation by $\mathrm{OH}$ at $9.4( \pm 1.3) \mathrm{Tg} \mathrm{a}^{-1}$ and the $\mathrm{NH}$ soil sink therefore is $62( \pm 10) \mathrm{Tg} \mathrm{a}^{-1}$. The uncertainty is calculated by error propagation for every parameter that was used in the calculation.

Finally, to estimate the global soil sink, we need to know the inter-hemispheric ratio of the "effective" soil surface area where $\mathrm{H}_{2}$ uptake occurs. Since $\mathrm{H}_{2}$ uptake is mainly controlled by diffusion through soil voids (Yonemura et al., 2000b), inundation and snow-cover of soil surface prevent $\mathrm{H}_{2}$ uptake. Therefore, the annual mean land areas excluding wetlands, rice paddies, glaciers, and snow-covered regions provide a ratio of the effective soil surface areas of $\mathrm{SH}$ to $\mathrm{NH}$ as $0.4( \pm 0.03)$ (Table 4$)$. This in turn leads to the global soil sink strength of $88( \pm 11) \mathrm{Tg} \mathrm{a}^{-1}$ since the fraction of soil uptake $(h)$ of the $\mathrm{H}_{2}$ sink in the $\mathrm{SH}$ can be derived by $h=\frac{g \beta}{1-g(1-\beta)}$ accounting for the area dependency of soil sink, where $\beta$ is the ratio of effective soil surface area of the SH to the $\mathrm{NH}$. The value we calculated is $57 \%$ greater than the most recent estimate (Novelli et al., 1999). The derived global sink strength of $107( \pm 11) \mathrm{Tg} \mathrm{a}^{-1}$ implies the mean lifetime of $\mathrm{H}_{2}$ in the troposphere to be $1.4( \pm 0.2)$ years, considerably shorter than the previous estimate of $\sim 2$ years. 
Table 4. Surface areas $\left(\times 10^{6} \mathrm{~km}^{2}\right)$ for several types of land in the Northern (NH) and Southern Hemisphere (SH).

\begin{tabular}{llll}
\hline & NH & SH & Reference \\
\hline Continental area & 103 & 46 & Butcher et al. (1992) \\
Snow-cover & $23.1 \pm 4.8$ & $14.5^{\S}$ & Armstrong and Brodzik (2001) and Dewey and Heim (1983) \\
Wetlands $^{\dagger}$ & $4.1 \pm 0.2$ & $1.6 \pm 0.3$ & Aselmann and Crutzen (1989) \\
Rice paddies $^{\dagger}$ & $1.3 \pm 0.2$ & - & Aselmann and Crutzen (1989) \\
\hline Effective soil surface & $74.5 \pm 4.9$ & $30.0 \pm 0.3$ & \\
\hline
\end{tabular}

$\S$ Including the area of Antarctica $\left(=14 \times 10^{6} \mathrm{~km}^{2}\right)$.

$\ddagger$ The uncertainty of the wetlands is assumed to be the difference of areas estimated by Aselmann and Crutzen (1989) and Matthews and Fung (1987).

$\dagger$ The uncertainty of rice paddy area is assumed to be the difference of areas estimated by Aselmann and Crutzen (1989) and FAO Regional Office for Asia and Pacific (2003).

4.3 Effect of variable $\delta \mathrm{D}$ of source $\mathrm{H}_{2}$ and the hemispheric exchange of air mass on the estimation of soil uptake rate

Among the sources, the $\delta \mathrm{D}$ value of the $\mathrm{H}_{2}$ from photochemical reactions of volatile organic compounds (VOCs) may vary due to change in the $\delta \mathrm{D}$ value of the VOCs involved, and due to the change in the $\mathrm{OH}$ concentration along the year. The annual variation of the $\delta \mathrm{D}$ value of $\mathrm{CH}_{4}$, the longestlived VOC and a dominant source of $\mathrm{H}_{2}$, shows only $\sim 2 \%$ o amplitude (Bergamaschi et al., 2000). This suggests insignificant seasonal variation of the $\delta \mathrm{D}$ value of combined VOCs unless the $\delta \mathrm{D}$ values of primary sources (e.g. biosphere) of non-methane volatile organic compounds (NMVOCs) would change much. This however is unlikely. The annual variation of the $\mathrm{OH}$ concentration on the hemispheric scale is substantial, however (Spivakovsky et al., 2000). Formaldehyde $\left(\mathrm{CH}_{2} \mathrm{O}\right)$, the very last precursor of $\mathrm{H}_{2}$ in the photochemical reaction chain, has two channels of photolysis, one of which produces $\mathrm{H}_{2}$ and $\mathrm{CO}$ molecules and the other $\mathrm{H}$ and $\mathrm{CHO}$ radicals. A fraction also reacts with $\mathrm{OH}$ in the atmosphere. The yield of $\mathrm{H}_{2}$ and its corresponding $\delta \mathrm{D}$ value depend on the fraction of $\mathrm{CH}_{2} \mathrm{O}$ that reacts with $\mathrm{OH}$ because the quantum yields for the two channels of $\mathrm{CH}_{2} \mathrm{O}$ photolysis are nearly constant along year in the troposphere. The fraction of $\mathrm{CH}_{2} \mathrm{O}$ that reacts with $\mathrm{OH}$ varies from 14 to $21 \%$ when using the photolysis rates of the two channels in the troposphere calculated by a 2-dimensional model (Bruehl and Crutzen, 1993), the rate constant of $\mathrm{CH}_{2} \mathrm{O}$ (Sander et al., 2003), and the monthly OH concentration (Spivakovsky et al., 2000) normalized to the global mean value (Prinn et al., 1995). The $\delta \mathrm{D}$ values of the $\mathrm{H}_{2}$ that is produced by photolysis result in peak-to-peak variation of $\sim 20 \%$ o according to the scheme of isotopic fractionation between $\mathrm{CH}_{4}$ and $\mathrm{H}_{2}$ under tropospheric condition (Rhee et al., 2006) ${ }^{1}$. A onebox model simulation shows that the change in $\alpha_{\text {app }}$ remains within its uncertainty when including this seasonal variation of $\delta \mathrm{D}$ and given the source and sink strengths in the $\mathrm{NH}$ and their characteristic isotopic signatures, except the $\mathrm{H}_{2}$ from the ocean and nitrogen fixation, in Table 1, and the seasonalities in Hauglustaine and Ehhalt (2002) (Fig. 3). In order to adjust the $\delta \mathrm{D}$ values of the atmospheric $\mathrm{H}_{2}$ in the model to that observed $(\sim 126 \%)$, the isotopic signatures for the $\mathrm{H}_{2}$ from the ocean and nitrogen fixation were increased to $-500 \%$ in the model. No difference in $\alpha_{\text {app }}$ arises by this change because we assume no seasonal variation in these two emission strengths.

Along with the calculation above, we consider the $\mathrm{NH}$ as an isolated compartment. Nevertheless, although the two hemispheres are effectively blocked by the ITCZ, the mean timescale of inter-hemispheric mixing of $\sim 1$ year potentially leads to a SH influence because it is similar in magnitude to the lifetime of atmospheric $\mathrm{H}_{2}$. To examine the effect of inter-hemispheric exchange we applied a two-box model assuming that the $\mathrm{NH}$ and the $\mathrm{SH}$ are well-mixed compartments and that the seasonality of sources and sinks follows what Hauglustaine and Ehhalt (2002) described with the mean values in Table 1. In Fig. 3, the input functions of the source and sinks strengths in the two-box model simulation are depicted. Here again we used the characteristic isotopic signatures shown in Table 1, but for the $\mathrm{H}_{2}$ from the ocean and nitrogen fixation the values were adjusted to $-630 \%$ o by the same reason as for the 1-box model. It appears that

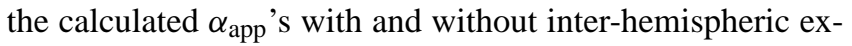
change are identical within the uncertainty estimated from the observations $(= \pm 0.02)$. This may be anticipated in face of the small seasonality of the source and sink strengths in the $\mathrm{SH}$, since the main influence of inter-hemispheric exchange comes from the difference of the hemispheric $\mathrm{H}_{2}$ mixing and isotopic ratios (since we assume the inter-hemispheric exchange rate is constant throughout the year). Although it is necessary to investigate the effects of the hemispheric exchange in a more realistic setup (e.g., 3-D model), this simple box model simulation suggests an insignificant effect of the SH influence on the determination of $\alpha_{\text {app }}$ and thus soil uptake rate. 

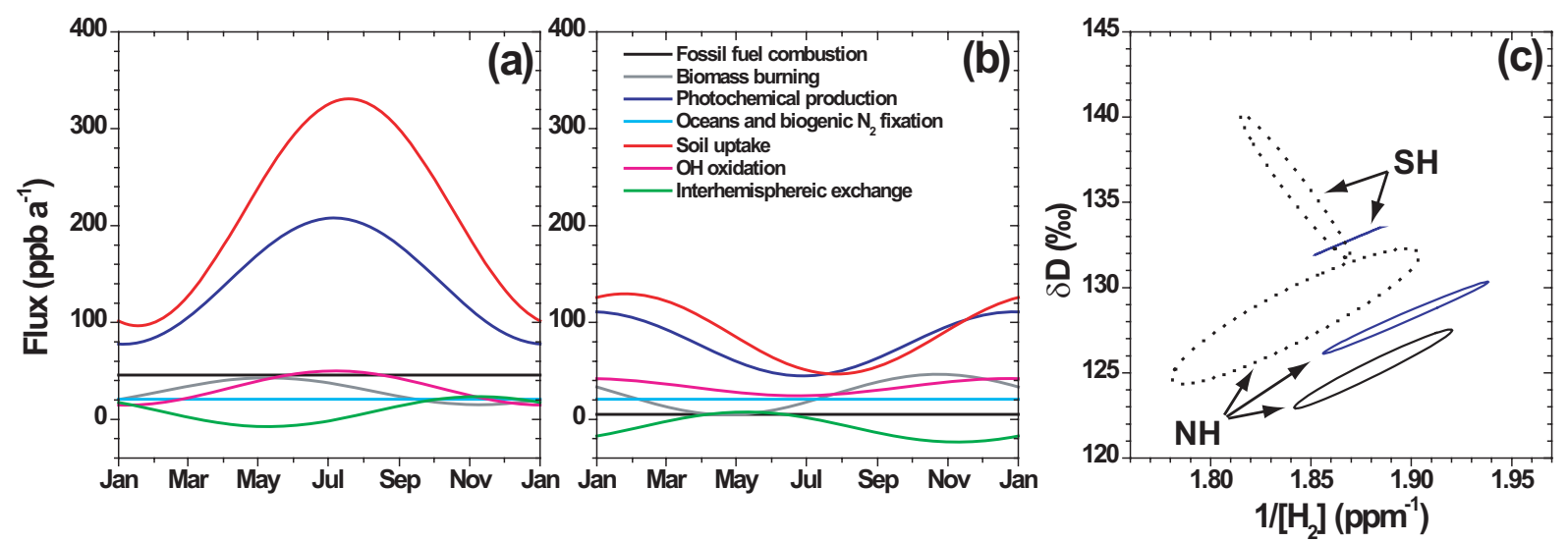

Fig. 3. Seasonal variation of source and sink strengths in (a) the Northern Hemisphere (NH) and (b) the Southern Hemisphere (SH) given in a two-box model. The seasonal variations of sources and sinks are from Hauglustaine and Ehhalt (2002). The inter-hemispheric exchange rates are calculated from the two-box model simulation. (c) Comparison of relations between $\delta \mathrm{D}$ and the inverse of the $\mathrm{H}_{2}$ mixing ratios from a one-box (black solid line) and two-box (blue solid line) models and the fits to the CARIBIC data (dotted line) shown in Fig. 2 (c and d).

\subsection{Southern hemispheric $\mathrm{H}_{2}$ cycle}

The in-phase variation of $\delta \mathrm{D}$ and $\mathrm{H}_{2}$ in the $\mathrm{SH}$ (Fig. 2d) indicates that its $\mathrm{H}_{2}$ cycle is not primarily driven by sink processes, in contrast to the $\mathrm{NH}$. Low $\mathrm{H}_{2}$ mixing ratios and $\delta \mathrm{D}$ values during $\mathrm{SH}$ winter demonstrate the minor role of soil uptake. The effective soil surface area in the SH is significantly smaller (Table 4), and its seasonal variation also is negligible on account of the small snow-cover extent $(\sim 1 \%)$ (Dewey and Heim, 1983). Also there is little seasonal variation in soil temperature because most of the continental area is at low latitudes. These factors render the $\mathrm{SH} \mathrm{H}_{2}$ cycle much weaker with a slower rate of turnover compared to the NH (Table 3). Therefore, this SH winter anomaly of the $\mathrm{H}_{2}$ cycle must have an external influence. Seasonal observations of NH tracers (chiefly, $\mathrm{SF}_{6}$ (Levin and Hesshaimer, 1996), CFCs (Prather et al., 1987), ${ }^{85} \mathrm{Kr}$ (Jacob et al., 1987), $\mathrm{CO}_{2}$ (Nakazawa et al., 1991)) in the SH show a strong NH influence during the $\mathrm{SH}$ winter following the northward shift of the ITCZ several months earlier. Moreover, the monsoon circulation enhances the injection of $\mathrm{NH}$ air into the south through the upper troposphere (Nakazawa et al., 1991; Newell et al., 1997). This NH air mass being supplied with the boundary layer air through convection near ITCZ has lower $\mathrm{H}_{2}$ mixing ratios and is isotopically lighter than the $\mathrm{SH}$ air. We infer that this $\mathrm{NH}$ influence causes the $\mathrm{H}_{2}$ and $\delta \mathrm{D}$ of the $\mathrm{SH}$ air to reach their lowest values simultaneously. In $\mathrm{SH}$ summer, however, the monsoon circulation is suppressed with the shift of the ITCZ to the south so that the NH influence tends to be minimal.

The synchronous increase of $\mathrm{H}_{2}$ and $\delta \mathrm{D}$ in $\mathrm{SH}$ late spring and early summer suggests the major source of $\mathrm{H}_{2}$ in the $\mathrm{SH}$ to be isotopically heavier than the atmospheric $\mathrm{H}_{2}$ reservoir itself. It has been postulated that biomass burning dominates the SH seasonal cycle of $\mathrm{H}_{2}$ (Hauglustaine and Ehhalt, 2002; Novelli et al., 1999). In particular, the increase of $\mathrm{H}_{2}$ in $\mathrm{SH}$ late spring and early summer makes this plausible as it coincides with the biomass burning period in the SH. However, the seasonal cycle of $\delta \mathrm{D}$ based on CARIBIC contradicts this hypothesis, unless $\delta \mathrm{D}$ of $\mathrm{H}_{2}$ from biomass burning would be much higher than previously estimated using a laboratory experiment (Gerst and Quay, 2001).

\section{5 $\delta \mathrm{D}$ of the $\mathrm{H}_{2}$ emitted from biomass burning}

Our data allow an independent estimate of $\delta \mathrm{D}$ of $\mathrm{H}_{2}$ from biomass burning. As mentioned, during all three flight sections in the equatorial tropics the aircraft intercepted air masses carrying entrained boundary layer air (Fig. 1). The observed enhancement of $\mathrm{CO}$ and its actual isotopic compositions of ${ }^{13} \mathrm{CO}, \mathrm{C}^{18} \mathrm{O}$, and ${ }^{14} \mathrm{CO}$ (not shown) demonstrate a dominant influence of biomass burning effluents. The latter will be discussed and presented in detail elsewhere. In strong contrast to this, $\mathrm{H}_{2}$ mixing ratios actually do not reflect the enhancement of $\mathrm{CO}$. For instance, in July, $\mathrm{H}_{2}$ and $\delta \mathrm{D}$ both were lower in the equatorial tropics whereas $\mathrm{CO}$ increased to $200 \mathrm{ppb}$ due to biomass burning (Mühle et al., 2002). Therefore, there must be a counterbalance to the emissions of $\mathrm{H}_{2}$ from biomass burning, e.g. $\mathrm{H}_{2}$ uptake by soil. Another cause one could think of is a substantial photochemical loss due to increased $\mathrm{OH}$. This however can be ruled out because the reaction rate constant of $\mathrm{H}_{2}$ with $\mathrm{OH}$ is $\sim 50$ times slower than that for CO.

We estimate $\delta \mathrm{D}$ of $\mathrm{H}_{2}$ from biomass burning based on mass conservation for the major $(\mathrm{H})$ and minor (D) isotopes of $\mathrm{H}_{2}$ in one box in which $\mathrm{H}_{2}$ is emitted from biomass burning and destroyed on soil surface accompanied with the 

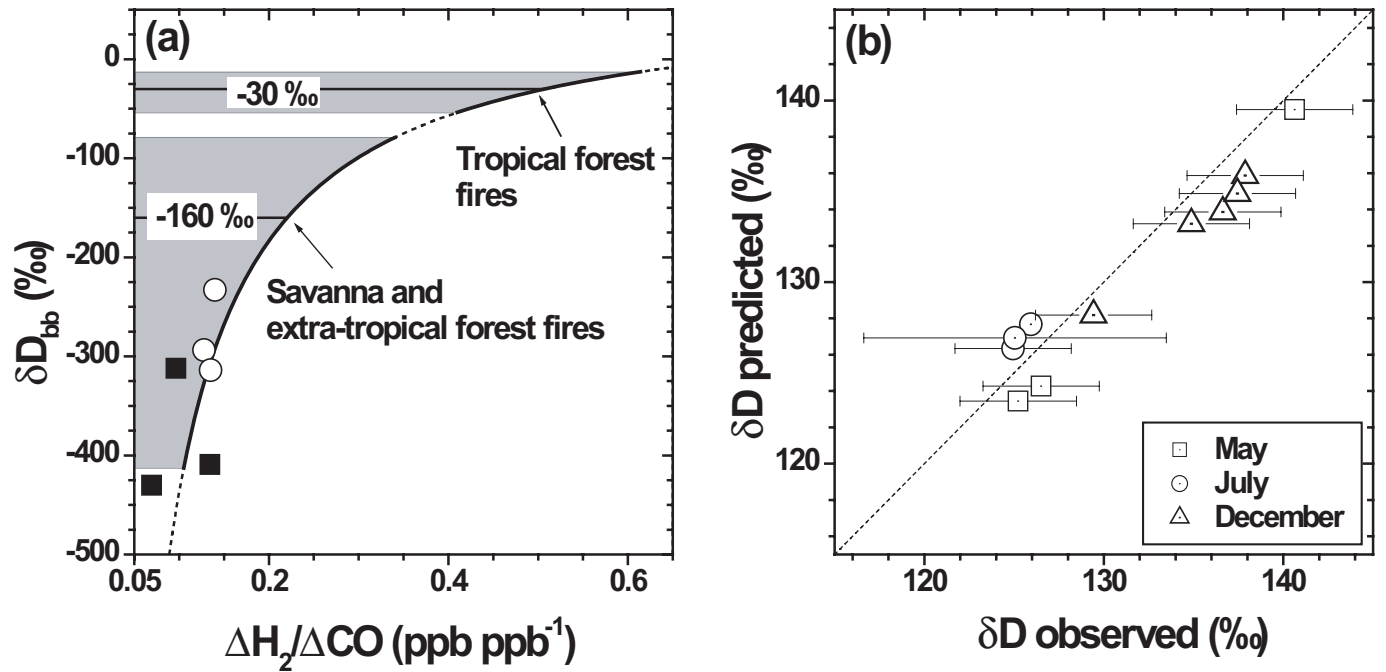

Fig. 4. (a) The deuterium (D) content of $\mathrm{H}_{2}$ emitted from biomass burning $\left(\delta \mathrm{D}_{\mathrm{bb}}\right)$ as a function of the emission ratio $\left(E R=\Delta \mathrm{H}_{2} / \Delta \mathrm{CO}\right)$ derived from the model. The dotted curve depicts the relation between $\delta \mathrm{D}_{\mathrm{bb}}$ and ER predicted by the model $\left(\delta \mathrm{D}_{\mathrm{bb}} \approx 70-\frac{51}{\mathrm{ER}}\right)$. The fat sections of the dotted curve confine the range of ERs for the tropical, extra-tropical, and savanna regions. The ERs for these regions are after Andreae and Merlet (2001). The gray shaded areas highlight the corresponding range of $\delta \mathrm{D}$. The $\delta \mathrm{D}$ values of $-30 \%$ and $-160 \%$ o corresponds to the mean of ERs for the tropical forest fires and the extra-tropical and savanna fires, respectively. The symbols indicate the results from a laboratory experiment (Gerst and Quay, 2001) with Idaho white pine needles (solid squares) and Lodgepole pine branches (open circles). (b) Comparison of $\delta \mathrm{D}$ from the model prediction and the observation in the equatorial tropics for all 3 flights. The dotted line is one-to-one relation.

isotopic fractionation:

$\left[\mathrm{H}_{2}\right]_{\mathrm{ob}}=\left[\mathrm{H}_{2}\right]_{\mathrm{bg}}-\left[\mathrm{H}_{2}\right]_{\mathrm{sl}}+\left[\mathrm{H}_{2}\right]_{\mathrm{bb}}$

$\begin{aligned} \delta \mathrm{D}_{\mathrm{ob}} & =\left(\left(\delta \mathrm{D}_{\mathrm{bg}}+1000\right) \times\left(1-g_{\mathrm{sl}}\right)^{\alpha-1}-1000\right) \\ & \times\left(1-f_{\mathrm{bb}}\right)+\delta \mathrm{D}_{\mathrm{bb}} \times f_{\mathrm{bb}}\end{aligned}$

where $\left[\mathrm{H}_{2}\right]_{i}$ is the $\mathrm{H}_{2}$ mixing ratio, $\alpha$ is the isotopic fractionation factor for $\mathrm{H}_{2}$ removal by soil uptake (Gerst and Quay, 2001; Rahn et al., 2002a), $f_{\text {bb }}$ is the ratio of $\mathrm{H}_{2}$ emitted from biomass burning to the $\mathrm{H}_{2}$ mixing ratio observed $\left(=\frac{\left[\mathrm{H}_{2}\right]_{\mathrm{bb}}}{\left[\mathrm{H}_{2}\right]_{\mathrm{ob}}}\right), g_{\mathrm{sl}}$ is the ratio of $\mathrm{H}_{2}$ consumed by soil to the background $\mathrm{H}_{2}$ mixing ratios $\left(=\frac{\left[\mathrm{H}_{2}\right]_{\mathrm{sl}}}{\left[\mathrm{H}_{2}\right]_{\mathrm{bg}}}\right)$, and indices are: $\mathrm{ob}(\mathrm{ob}-$ servation); bg (background); bb (biomass burning); sl (soil uptake). In applying this model to our observations in the equatorial tropics we assume (1) that the background mixing ratios of $\mathrm{CO}\left([\mathrm{CO}]_{\mathrm{bg}}\right)$ and $\mathrm{H}_{2}\left(\left[\mathrm{H}_{2}\right]_{\mathrm{bg}}\right)$ are the same as for the adjacent air sample to the southern or northern free troposphere. In the case of the air sample in the middle of the equatorial tropics, the mean values of both air samples are representative except the air samples collected in the latitude of $6.3^{\circ} \mathrm{N}$ in May and $12.6^{\circ} \mathrm{S}$ in December. According to the 5-day backward trajectories (see the web site www.knmi.nl/ samenw/campaign_support/CARIBIC/190500 and /031200), these air masses in May and December originated in the $\mathrm{NH}$ and the SH, respectively. We further assume (2) that the increase of the $\mathrm{CO}$ mixing ratio as observed in the equatorial tropics is solely due to the emissions from biomass burning, (3) that the CO uptake by soil is negligible, (4) that other anthropogenic emissions and the photochemical oxidation and production of $\mathrm{H}_{2}$ by the $\mathrm{OH}$ radical are not significant, and (5) that in the background air parcel $\mathrm{H}_{2}$ was consumed by soil prior to uplifting and mixing with a plume from biomass burning.

We draw a relation between the emission ratio of $\mathrm{H}_{2}$ to $\mathrm{CO}\left(\mathrm{ER}=\Delta \mathrm{H}_{2} / \Delta \mathrm{CO}=\frac{\left[\mathrm{H}_{2}\right]_{\mathrm{bb}}}{[\mathrm{CO}]_{\mathrm{bb}}}\right.$ and $\left.[\mathrm{CO}]_{\mathrm{bb}}=[\mathrm{CO}]_{\mathrm{ob}}-[\mathrm{CO}]_{\mathrm{bg}}\right)$ and $\delta \mathrm{D}_{\mathrm{bb}}$ by using a least squares minimization between the modeled and the observed $\delta \mathrm{D}\left(\delta \mathrm{D}_{\mathrm{ob}}\right)$ at a given ER value. Repeating this procedure at different ER value, one can obtain an inverse relation between ER and $\delta \mathrm{D}_{\mathrm{bb}}$ as shown in Fig. 4a. While optimizing the model to the observation, 2 data points that result in negative values of $g_{s 1}$ are excluded (WAS-25-6 and WAS-30-6, see Table 2). This artifact is mainly due to the large $\left[\mathrm{H}_{2}\right]_{\mathrm{ob}}$ despite small addition of $\left[\mathrm{H}_{2}\right]_{\mathrm{bb}}$. On the other hand, this inverse relation between $\delta \mathrm{D}_{\mathrm{bb}}$ and ER could be derived directly by combining Eqs. (2) and (3) and applying a Taylor series expansion given the $\mathrm{H}_{2}$ emission from biomass burning or $\mathrm{H}_{2}$ uptake by soils are not extremely large:

$\delta \mathrm{D}_{\mathrm{bb}} \approx \frac{\frac{\left[\mathrm{H}_{2}\right]_{\mathrm{ob}}}{[\mathrm{CO}]_{\mathrm{bb}}}\left(\delta \mathrm{D}_{\mathrm{ob}}-\delta \mathrm{D}_{\mathrm{bg}}\right)}{\mathrm{ER}}+\alpha \delta \mathrm{D}_{\mathrm{bg}}+\varepsilon$

where $\varepsilon=(\alpha-1) \times 1000$. Note that this verifies only the inverse relationship obtained by the fit to the observation. 
Since there are several unknowns in equation (4), we cannot apply it to derive $\delta \mathrm{D}_{\mathrm{bb}}$ at an ER value.

As Fig. 4a shows, the model results appear to be in good agreement with the only available set of laboratory measurements taking into account the scatter of the ER of $\mathrm{H}_{2}$ from biomass burning for the same biomass material (Gerst and Quay, 2001). This agreement, within the uncertainty, between the observed and the predicted $\delta \mathrm{D}$ strongly confirms the correctness of the model (Fig. 4b) and encourages us to apply the model on a global scale. As our model shows, the $\delta \mathrm{D}$ value of $\mathrm{H}_{2}$ from biomass burning differs depending on the actual region (Fig. 4a). Since it is known that soil moisture $\delta \mathrm{D}$ values determine to a high degree $\delta \mathrm{D}$ of the hydrogen in plant organic matter (Yapp and Epstein, 1982), it is plausible to assume that $\delta \mathrm{D}$ of $\mathrm{H}_{2}$ from biomass burning follows the gradient of $\delta \mathrm{D}$ in meteoric water with latitude (Dansgaard, 1964). Besides, the isotopic fractionation during the burning process may be an additional cause to lower the deuterium content in the $\mathrm{H}_{2}$ (Gerst and Quay, 2001). Our model shows that tropical forest fires emit $\mathrm{H}_{2}$ with a high $\delta \mathrm{D}$ value of $-30( \pm 20) \%$ and extra-tropical forest and savanna fires have values of $-150( \pm 100) \%$ and $-170( \pm 120) \%$, respectively. Weighting the emission rates in those regions (Andreae and Merlet, 2001), we compute the global mean $\delta \mathrm{D}$ value of $-90( \pm 40) \%$. This value is much higher than the previous estimate of a global mean value of $-290( \pm 60) \%$ (Gerst and Quay, 2001). Nevertheless, our model still predicts that biomass burning emits $\mathrm{H}_{2}$ that is isotopically lighter than the atmospheric $\mathrm{H}_{2}$ reservoir itself. Therefore, direct emission of $\mathrm{H}_{2}$ from biomass burning is not the primary source for the increase of $\mathrm{H}_{2}$ in $\mathrm{SH}$ summer. The photochemical oxidation of $\mathrm{CH}_{4}$ and probably many NMVOCs constitute a specific source that maintains the atmospheric $\mathrm{H}_{2}$ reservoir isotopically heavy. Biomass burning also emits VOCs that can be photochemically degraded to produce $\mathrm{H}_{2}$. Our results indicate that the secondary photochemical production of $\mathrm{H}_{2}$ from the VOCs emitted from biomass burning and biosphere must play a substantial role in the seasonal cycle of $\mathrm{H}_{2}$ in the $\mathrm{SH}$ and further in the global budget of tropospheric $\mathrm{H}_{2}$.

\subsection{Global $\mathrm{H}_{2}$ source strengths}

Although it has been debated whether the global $\mathrm{H}_{2}$ budget is in steady state or not (Khalil and Rasmussen, 1990; Novelli et al., 1999; Simmonds et al., 2000), the results from the NOAA/CMDL observations over the last decade (Novelli et al., 1999) show no significant inter-annual variation or trend in either hemisphere. In assuming steady state for $\delta \mathrm{D}$ as well, the global $\left(\delta \mathrm{D}_{\mathrm{QG}}\right), \mathrm{NH}\left(\delta \mathrm{D}_{\mathrm{QN}}\right)$, and $\mathrm{SH}\left(\delta \mathrm{D}_{\mathrm{QS}}\right)$ source values of $\delta \mathrm{D}$ are derived (Table 1) while taking into account the asymmetric hemispheric distribution of $\mathrm{H}$ and $\mathrm{D}$ :

$$
\delta \mathrm{D}_{\mathrm{QG}}=\frac{\sum_{j} L_{j \mathrm{~N}}\left(\alpha_{j} \delta \mathrm{D}_{\mathrm{N}}+\varepsilon_{j}\right)+\sum_{j} L_{j \mathrm{~S}}\left(\alpha_{j} \delta \mathrm{D}_{\mathrm{S}}+\varepsilon_{j}\right)}{\sum_{j} L_{j}}
$$

$$
\delta \mathrm{D}_{\mathrm{QN}}=\frac{\sum_{j} L_{j \mathrm{~N}}\left(\alpha_{j} \delta \mathrm{D}_{\mathrm{N}}+\varepsilon_{j}\right)-k m \frac{\delta \mathrm{D}_{\mathrm{S}}-\gamma \delta \mathrm{D}_{\mathrm{N}}}{1+\gamma}}{\sum_{j} L_{j \mathrm{~N}}-k m \frac{1-\gamma}{1+\gamma}}
$$

$$
\delta \mathrm{D}_{\mathrm{QS}}=\frac{\sum_{j} L_{j \mathrm{~S}}\left(\alpha_{j} \delta \mathrm{D}_{\mathrm{S}}+\varepsilon_{j}\right)+k m \frac{\delta \mathrm{D}_{\mathrm{S}}-\gamma \delta \mathrm{D}_{\mathrm{N}}}{1+\gamma}}{\sum_{j} L_{j \mathrm{~S}}+k m \frac{1-\gamma}{1+\gamma}}
$$

The subscripts indicate: $\mathrm{G}$ (global); N (Northern Hemisphere); S (Southern Hemisphere); Q (source); $j$ (respective sink processes). Further, $L_{j}$ is the sink strength, $\alpha_{j}$ are the isotopic fractionation factors for sink processes, $\varepsilon_{j}$ is $\left(\alpha_{j}-1\right) \times 1000, k$ is the hemispheric exchange rate $\left(=1 \mathrm{yr}^{-1}\right)$ (Jacob et al., 1987), $m$ is the tropospheric burden of $\mathrm{H}_{2}$ $(=155 \mathrm{Tg}$ ) (Novelli et al., 1999), and $\gamma$ is the ratio of the $\mathrm{H}_{2}$ burdens in the NH to $\mathrm{SH}(=0.97)$ (Novelli et al., 1999). The right-hand side of denominator and numerator in the equations for $\delta \mathrm{D}_{\mathrm{QN}}$ and $\delta \mathrm{D}_{\mathrm{QS}}$ play a role in the imbalance of the $\mathrm{H}_{2}$ source strength in both hemispheres. Inserting the values into the equations, the isotopic signatures of combined sources are: $\delta \mathrm{D}_{\mathrm{QG}}=-7.2 \%, \delta \mathrm{D}_{\mathrm{QN}}=-2.6 \%$, and $\delta \mathrm{D}_{\mathrm{QS}}=-16 \%$. The calculation of these values does not account for the input of stratospheric $\mathrm{H}_{2}$ providing that the tropospheric and stratospheric $\mathrm{H}_{2}$ mixing ratios are the same (Ehhalt et al., 1977). However, stratospheric $\mathrm{H}_{2}$ is more enriched in D than tropospheric $\mathrm{H}_{2}$ (Rahn et al., 2003; Röckmann et al., 2003), leading to input of D from the stratosphere. We estimate the mean $\delta \mathrm{D}$ value of stratospheric $\mathrm{H}_{2}(=168 \%)$ at the stratospheric mean $\mathrm{CH}_{4}(=1640 \mathrm{ppb})$ on the basis of their mutual linear relation (Röckmann et al., 2003). Multiplying the difference of the $\delta \mathrm{D}$ values between the stratosphere and the troposphere (e.g. for $\mathrm{NH}$, $\delta \mathrm{D}_{\mathrm{SS}}-\delta \mathrm{D}_{\mathrm{NH}}=40 \%$ o) to the fraction of the $\mathrm{H}_{2}$ flux across the tropopause at the $380 \mathrm{~K}$ isentropic surface (e.g., for $\mathrm{NH}$, $\left.\mathrm{F}_{\mathrm{SS}-\mathrm{NH}}=12.5 \mathrm{Tg}\left(\mathrm{H}_{2}\right) \mathrm{a}^{-1}\right)$ to the annual $\mathrm{H}_{2}$ turnover rate in each hemisphere, the increase of $\delta \mathrm{D}$ in the $\mathrm{NH}$ and $\mathrm{SH}$ will be $7 \%$ and $11 \%$, respectively. Accounting for the impact of stratospheric input, $\delta \mathrm{D}_{\mathrm{QN}}$ would be $\sim 5 \%$, which is similar to the $\delta \mathrm{D}$ of combined source $(=10 \%)$ obtained in Fig. 5 applying the Rayleigh distillation model (see Appendix B). This clearly supports the isotopic equilibrium of the $\mathrm{NH} \mathrm{H}_{2}$ cycle and underscores the robust approach of our $\mathrm{H}_{2}$ budget estimation. In contrast, the $\mathrm{SH} \mathrm{H}_{2}$ cycle does not reach isotopic equilibrium, but is perturbed by the $\mathrm{NH}$ intrusion as $\delta \mathrm{D}_{\mathrm{QS}}$ is far different from the value of $390 \%$ derived from the observations (Fig. 5). 
The asymmetric distribution of the isotopes of $\mathrm{H}_{2}$ in the two hemispheres allows us to estimate the contribution of sources between the hemispheres according to:

$\delta \mathrm{D}_{\mathrm{QG}}=f \delta \mathrm{D}_{\mathrm{QN}}+(1-f) \delta \mathrm{D}_{\mathrm{QS}}$

The NH fraction of the global $\mathrm{H}_{2}$ source strength, $f=0.65$, turns out to be the same as that for the $\mathrm{NH}$ fraction of the global CO source (e.g. Logan et al., 1981), which is commonly used as a surrogate for the source strength of atmospheric $\mathrm{H}_{2}$. The values for $f, \delta \mathrm{D}_{\mathrm{QG}}$, and $\delta \mathrm{D}_{\mathrm{QN}}$ (or $\delta \mathrm{D}_{\mathrm{QS}}$ ) constrain the estimates of the global and hemispheric source strengths in conjunction with the isotopic signature of each source $\left(\delta \mathrm{D}_{i}\right)$ and the $\mathrm{NH}$ fraction of the global source strength $\left(\chi_{i}\right)$ :

$$
\begin{aligned}
& \sum_{i} q_{i}=1 \\
& \sum_{i} \chi_{i} q_{i}=f \\
& \sum_{i} \delta \mathrm{D}_{i} q_{i}=\delta \mathrm{D}_{\mathrm{QG}}-\zeta\left(\delta \mathrm{D}_{\mathrm{SS}}-\delta \mathrm{D}_{\mathrm{TS}}\right) \\
& \sum_{i} \chi_{i} \delta \mathrm{D}_{i} q_{i}=f\left\{\delta \mathrm{D}_{\mathrm{QN}}-\zeta_{\mathrm{N}}\left(\delta \mathrm{D}_{\mathrm{SS}}-\delta \mathrm{D}_{\mathrm{N}}\right)\right\}
\end{aligned}
$$

where $q_{i}$ indicates the fraction of source $i, \zeta$ is the ratio of the $\mathrm{H}_{2}$ flux across the tropopause at the $380 \mathrm{~K}$ isentropic surface (Appenzeller et al., 1996) to the annual $\mathrm{H}_{2}$ turnover rate, $\zeta_{N}$ is the same parameter as $\zeta$ but for the $\mathrm{NH}, \delta \mathrm{D}_{\mathrm{SS}}$ is the value for the stratospheric $\mathrm{H}_{2}, \delta \mathrm{D}_{\mathrm{TS}}$ is the mean value for the tropospheric $\mathrm{H}_{2}, \delta \mathrm{D}_{\mathrm{N}}$ is the mean value for the Northern Hemispheric $\mathrm{H}_{2} . \delta \mathrm{D}_{i}$ 's are available from the literature and this study (see Table 1).

The fraction $\chi_{i}$ for fossil fuel combustion is estimated from the updated Emission Database for Global Atmospheric Research (EDGAR) CO emission inventories (Oliver and Berdowski, 2001). The fraction $\chi_{i}$ for biomass burning reflects the ratios of $\mathrm{CO}$ emissions from biomass burning in the two hemispheres (Duncan et al., 2003), while $\chi_{i}$ for ocean and microbial $\mathrm{N}_{2}$ fixation are based on the ratios of land and ocean (Levitus, 1982). The fraction $\chi_{i}$ for the photochemical production is uncertain particularly because of the large uncertainty in the amount of $\mathrm{H}_{2}$ produced by photochemical oxidation of NMVOCs. Thus, this parameter is considered unknown, and is confined by our observations of $\mathrm{H}_{2}$ and $\delta \mathrm{D}$ in the $\mathrm{SH}$. As discussed, the photochemical production of $\mathrm{H}_{2}$ was larger than that from biomass burning during the peak biomass burning period (late spring and early summer) in the SH. Assuming that $\mathrm{H}_{2}$ emission from biomass burning concentrates during this period, we estimate the photochemical production of $\mathrm{H}_{2}\left(P_{h v}\right)$ in this season considering that VOCs concentrations $\left(\left[\mathrm{VOC}_{i}\right]\right)$, the $\mathrm{OH}$ concentration ([OH]), and the fraction of $\mathrm{CH}_{2} \mathrm{O}$ that photolyzed to produce $\mathrm{H}_{2}\left(\phi_{i}\left(\mathrm{H}_{2}\right)\right)$ are key factors controlling $\mathrm{H}_{2}$ production
$\left(P_{h v}=\sum_{i} k_{i}[\mathrm{OH}]\left[\mathrm{VOC}_{i}\right] \phi_{i}\left(\mathrm{H}_{2}\right)\right.$, where $k_{i}$ is rate constant for the reaction of $\mathrm{VOC}_{i}$ and $\mathrm{OH}$ ). $\mathrm{CH}_{4}$ and isoprene may be major VOCs producing $\mathrm{H}_{2}$ in the atmosphere, and both do not have substantial seasonal variation in the $\mathrm{SH}$. Therefore, we presume an annual mean in this season. The $\mathrm{OH}$ concentration in the SH from November to January is 30\% greater than annual mean (Spivakovsky et al., 2000). A 2dimensional model calculation of photolysis rates of $\mathrm{CH}_{2} \mathrm{O}$ (Bruehl and Crutzen, 1993) and photochemical reaction rate of $\mathrm{CH}_{2} \mathrm{O}$ and $\mathrm{OH}$ indicate nearly constant fraction of $\mathrm{CH}_{2} \mathrm{O}$ to produce $\mathrm{H}_{2}$ along year. Therefore, over all photochemical production of $\mathrm{H}_{2}$ would be $\sim 30 \%$ greater in summer than annual mean, which results in $\sim 33(=1.3 / 4 \times 100) \%$ of the annual photochemical production of $\mathrm{H}_{2}$ during the biomass burning period in the SH. This implies that in the $\mathrm{SH}$ the biomass burning emission of $\mathrm{H}_{2}$ would be less than $~ 33 \%$ of the annual photochemical $\mathrm{H}_{2}$ production. This fraction should be considered as a lower limit because we assume the same VOCs concentrations as the annual mean, which might not be correct because biomass burning is one of the major sources of VOCs. Sensitivity test shows that $\chi_{i}$ for the photochemical production increases merely 0.02 with a factor of 2 increase (33\% to 66\%) in the fraction of $\mathrm{H}_{2}$ from biomass burning to the photochemical production of $\mathrm{H}_{2}$ in the $\mathrm{SH}$ because photochemical production is the major source of atmospheric $\mathrm{H}_{2}$ and occurs mainly in the NH (Table 1). However, the factor of 2 increase leads to $70 \%$ increase of biomass burning emissions and $10 \%$ decrease of the photochemical production of $\mathrm{H}_{2}$ on a global scale.

Finally, the source strengths are determined by means of mass conservation equations for the $\mathrm{H}$ and $\mathrm{D}$ isotopes of $\mathrm{H}_{2}$ on global and hemispheric scales. The uncertainties in the sources are estimated from the sensitivity runs with several $\delta \mathrm{D}$ values of sources from the literature. We adopt $\delta \mathrm{D}$ for fossil fuel combustions of $-270 \%$ (Rahn et al., 2002b) and $-196 \%$ o(Gerst and Quay, 2001), $\delta \mathrm{D}$ for biomass burning of $-90 \%$ (this study) and $-290 \%$ (Gerst and Quay, 2001), $\delta$ D for photochemical production of $213 \%$ (Rahn et al., 2003) and 113\%o (Gerst and Quay, 2001), $\delta \mathrm{D}$ for ocean and microbial $\mathrm{N}_{2}$ fixation of $-700 \%$ (Rahn et al., 2003) and half of it. Of the source strengths calculated we choose the uncertainty that results in the largest difference from the standard set of isotopic signatures shown in Table 1. For sink strengths, the uncertainties are propagated in each step of the calculation as mentioned earlier. As listed in Table 1, the individual source strengths calculated by our independent top-down approach are larger than the values previously estimated by Novelli et al. (1999). In particular, our study shows that the photochemical production of $\mathrm{H}_{2}$ is $60 \%$ higher than the former estimates (Novelli et al., 1999). The large anticipated input of $\mathrm{H}_{2}$ from photochemical oxidation indicates a substantial contribution by the photochemical oxidation of VOCs, which are ubiquitous atmospheric compounds (Singh et al., 2001, 2004). This also explains fairly homogeneous mixing ratios in both 


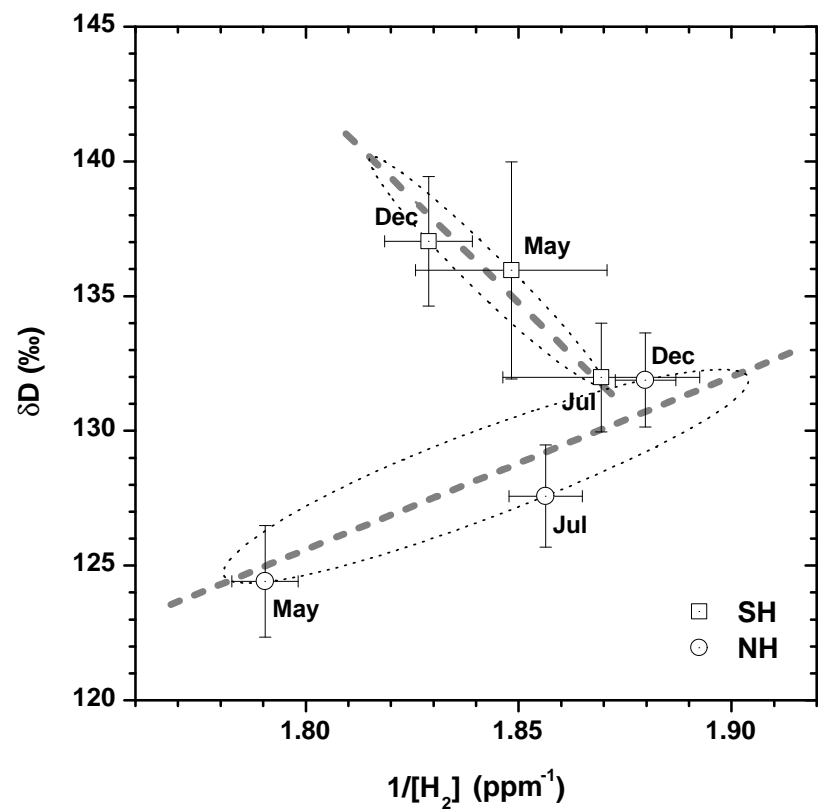

Fig. 5. Relationship between $\delta \mathrm{D}$ and the inverse of the $\mathrm{H}_{2}$ mixing ratios in the Southern and Northern Hemispheres. The error bars represent 1 standard deviation of the mean. The ellipses are derived from the sinusoidal fits of Fig. 2(c and d). The thick dashed lines represent the Rayleigh model. At isotopic equilibrium, its slope is related to the apparent isotopic fractionation factor and the intercept with the vertical axis represents the isotopic signature of all combined sources.

hemispheres in spite of short lifetime and major sink on soil surface.

\section{Conclusions}

Measurements of the stable isotope composition of free tropospheric $\mathrm{H}_{2}$ across the hemispheres allowed us to investigate atmospheric $\mathrm{H}_{2}$ cycle and budget on the global and hemispheric scale, be it with a limit of the number of observations. To our knowledge this is the first measurement of free tropospheric $\mathrm{H}_{2}$ covering both hemispheres. Although we have observed only during three discrete time slices, the spatial coverage of the air samples is large enough to represent the tropospheric $\mathrm{H}_{2}$ of the time slot in both hemispheres. It is important to note that our approach is largely independent of previous results and is not a bottom-up calculation. Undoubtedly, future observations and 3-D modeling shall further improve our understanding of global $\mathrm{H}_{2}$ cycle. The following is summary of our findings:

1. The $\mathrm{NH} \mathrm{H}_{2}$ cycle is mainly driven by the soil sink for which we conjecture the snow-cover extent to play a dominant role. The large peak-to-peak seasonal cycle of the NH snow-cover extent covering $\sim 40 \%$ of the $\mathrm{NH}$ continents, and its phase closely matching that of the cycle of the $\mathrm{NH} \mathrm{H}_{2}$ render our hypothesis plausible. Global warming may enhance the soil sink strength due to increasing soil temperatures and shrinking snowcover extent.

2. We determine the global soil sink strength to be $88( \pm 11) \mathrm{Tg} \mathrm{a}^{-1}$ using the seasonal variations of $\mathrm{H}_{2}$ and its $\mathrm{D} / \mathrm{H}$ ratio in the $\mathrm{NH}$. Since the two sink processes have strongly differing kinetic isotope effects, measurement of the D/H ratio allows the complex soil sink to be directly scaled against the better known photochemical sink. Our results reduce the uncertainty of the soil sink strength of $\mathrm{H}_{2}$, and in particular demonstrate that soil uptake is much stronger than previously estimated and dominates the global $\mathrm{H}_{2}$ cycle.

3. The $\mathrm{SH} \mathrm{H}_{2}$ cycle is mainly controlled by both photochemical production of $\mathrm{H}_{2}$ from variety sources of VOCs in summer and the NH intrusion enforced by monsoon circulation in winter, as is evidenced by inphase cycle of $\mathrm{D}$ and $\mathrm{H}$. This finding however contradicts the argument that biomass burning dominates the $\mathrm{SH} \mathrm{H}_{2}$ cycle which is based on the measurement of $\mathrm{H}_{2}$ mixing ratios (Novelli et al., 1999) and on a 3-D model study (Hauglustaine and Ehhalt, 2002).

4. The $\delta \mathrm{D}$ biomass burning signature appears to depend on the region, likely associated with the spatial gradient of $\delta \mathrm{D}$ in meteoric water (Dansgaard, 1964). Weighting the emission rates in various regions, the global mean value is estimated to be $-90( \pm 40) \%$. The value is far larger than a value estimated from a laboratory experiment (Gerst and Quay, 2001).

5. A top-down approach allowed us to independently determine the global and hemispheric source strengths being constrained by the sink strengths determined in this study and the characteristic isotopic compositions of sources. Our approach discloses far larger emissions of $\mathrm{H}_{2}$ from photochemical oxidation in the atmosphere than the previous estimates in terms of not only the absolute amounts $\left(64 \mathrm{Tg} \mathrm{a}^{-1}\right)$ but also the relative fraction (60\%) among all sources (Table 1).

\section{Appendix A Isotopic fractionation factor at isotopic equilibrium}

As stated in the text, we assume a system that maintains isotopic equilibrium for a given time period (i.e., one year), which satisfies the relationship, $\alpha=\frac{R_{Q}}{R_{r}}$. Here we elucidate that changes in source emissions within the given period of isotopic equilibrium do not influence the determination of $\alpha$ using a one-box model. Assuming a simple system with one 
sink and several sources of $\mathrm{H}_{2}$, isotopic mass balance can be described as

$$
\frac{d m}{d t}=\sum_{i} P_{i}-L
$$

and

$$
\frac{d m^{*}}{d t}=\sum_{i} P_{i} R_{i}-L \alpha R_{r}
$$

where $P$ is source, $L$ is sink, and $*$ indicates minor isotope of $\mathrm{H}_{2}$. Rearranging (A2a) with $m^{*}=R_{r} m$,

$$
\frac{d R_{r}}{d t}=\sum_{i} \frac{P_{i}}{m}\left(R_{i}-R_{r}\right)-\frac{L}{m}(\alpha-1) R_{r}
$$

At isotopic equilibrium, $d m / d t=0$ and $d R_{r} / d t=0$. Thus, $\alpha=\frac{\sum_{i} f_{i} R_{i}}{\frac{R_{r}}{P_{i}}}$ where $f_{i}$ is annual mean fraction of source $i$ $\left(f_{i}=\frac{\overline{P_{i}}}{\sum_{i} \overline{P_{i}}}\right.$, where $\overline{P_{i}}$ indicates annual mean of $\left.P_{i}\right)$. Under this condition, the source term in (A2b) becomes

$$
\sum_{i} P_{i}\left(R_{i}-R_{r}\right)=\sum_{i} P_{i}\left(\sum_{i} f_{i} R_{i}-R_{r}\right)
$$

Thus, as far as annual mean source strengths and the characteristic isotopic ratios are constant, the isotopic fractionation does not depend on the change in source strength within the given period (e.g., seasonality), but on the sink process.

\section{Appendix B A modification of the Rayleigh distillation model}

The change in the isotopic ratio of $\mathrm{H}_{2}$ by a fractionation process is described by the Rayleigh distillation model (Rayleigh, 1902):

$$
\frac{R_{f}}{R_{i}}=\left(\frac{C_{f}}{C_{i}}\right)^{\alpha-1}
$$

where $R_{i}$ and $C_{i}$ are the initial isotopic ratio and mixing ratio of $\mathrm{H}_{2}, R_{f}$ and $C_{f}$ are those observed along the fractionation process, and $\alpha$ is the isotopic fractionation factor. Equation (B1) can be converted by means of " $\delta$ " notation into:

$$
\ln \left(\frac{\delta \mathrm{D}_{f} \times 10^{-3}+1}{\delta \mathrm{D}_{i} \times 10^{-3}+1}\right)=(1-\alpha) \ln \left(\frac{C_{i}}{C_{f}}\right)
$$

This can be approximated by applying a Taylor series expansion as follows (Bergamaschi et al., 2000):

$\delta \mathrm{D}_{f} \approx \frac{\left(\delta \mathrm{D}_{i}+1000\right)(1-\alpha) C_{i}}{C_{f}}+\delta \mathrm{D}_{\mathrm{Q}}$

where $\delta \mathrm{D}_{\mathrm{Q}}=\alpha \delta \mathrm{D}_{i}+(\alpha-1) \times 1000$ which is the same expression as that derived from the definition of isotopic fractionation factor at isotopic equilibrium. According to Eq. (B3), one can obtain $\alpha$ from the slope of the relationship between $\delta \mathrm{D}$ and the inverse of the $\mathrm{H}_{2}$ mixing ratios observed during the isotopic fractionation. Equation (B3) also can be utilized to verify whether a system is at an isotopic equilibrium or not, because $\delta \mathrm{D}_{\mathrm{Q}}$ in (B3) depends on $\alpha$ and $\delta \mathrm{D}_{i}$ at isotopic equilibrium (e.g. Fig. 5).

Acknowledgements. We thank P. van Velthoven for the meteorological information along the flight transects, M. Hermann for the aerosol data, A. Zahn for $\mathrm{CO}$ and $\mathrm{O}_{3}$ data, P. J. Crutzen and P. Warneck for comments on manuscript, L. Ganzeveld for the estimation of soil areas, J. van Aardenne for EDGAR database, the carbon cycle group in NOAA/CMDL for the $\mathrm{H}_{2}$ data, and LTU International Airways for enabling CARIBIC. We thank P. Novelli for providing the data for the $\mathrm{NH}$ and $\mathrm{SH}$ that enabled the CARIBIC data to be not only compared with Mauna Loa, but also with hemispheric mean values, as was requested in review. This work was supported by grants from the Environmental Technologies RTD program of the commission of the European Communities DG XII (ENV4-CT95-0006 and EVK2-2001-00007) and the German Ministry for Education and Research (BMBF contract number 07ATF17, AF2000).

Edited by: Y. Rudich

\section{References}

Allan, W., Manning, M. R., Lassey, K. R., Lowe, D. C., and Gomez, A. J.: Modeling the variation of $\delta^{13} \mathrm{C}$ in atmospheric methane: Phase ellipses and the kinetic isotope effect, Global Biogeochem. Cycles, 15(2), 467-481, 2001.

Andreae, M. O. and Merlet, P.: Emission of trace gases and aerosols from biomass burning, Global Biogeochem. Cycles, 15(4), 955966, 2001

Appenzeller, C., Holton, J. R., and Rosenlof, K. H.: Seasonal variation of mass transport across the tropopause, J. Geophys. Res., 101(D10), 15 071-15 078, 1996.

Armstrong, R. L. and Brodzik, M. J.: Recent northern hemisphere snow extent: A comparison of data derived from visible and microwave satellite sensors, Geophys. Res. Lett., 28(19), 36733676, 2001.

Aselmann, I. and Crutzen, P. J.: Global distribution of natural freshwater wetlands and rice paddies, their net primary productivity, seasonality and possible methane emissions, J. Atmos. Chem., 8(4), 307-358, 1989.

Bergamaschi, P., Bräunlich, M., Marik, T., and Brenninkmeijer, C. A. M.: Measurements of carbon and hydrogen isotopes of atmospheric methane at Izãna, Tenerife: Seasonal cycles and synoptic-scale variations, J. Geophys. Res., 105(D11), 14531 14546, 2000.

Brenninkmeijer, C. A. M., Crutzen, P. J., Fischer, H., Gusten, H., Hans, W., Heinrich, G., Heintzenberg, J., Hermann, M., Immelmann, T., Kersting, D., Maiss, M., Nolle, M., Pitscheider, A., Pohlkamp, H., Scharffe, D., Specht, K., and Wiedensohler, A.: CARIBIC - Civil aircraft for global measurement of trace gases and aerosols in the tropopause region, J. Atmos. Ocean. Technol., 16(10), 1373-1383, 1999.

Bruehl, C. and Crutzen, P. J.: The Atmospheric Effects of Stratospheric Aircraft: Report of the 1992 Models and Measurements 
Workshop, Volume 1 - Workshop Objectives and Summary, in: NASA Reference Publication 1292, Vol. 1, edited by: Prather, M. J. and Remsberg, E. E., pp. 103-104, 1993.

Butcher, S. S., Charlson, R. J., Orians, G. H., and Wolfe, G. V.: Global Biogeochemical Cycles, 377 pp., Academic Press, London, 1992.

Conrad, R. and Seiler, W.: Contribution of hydrogen production by biological nitrogen fixation to the global hydrogen budget, J. Geophys. Res., 85(C10), 5493-5498, 1980.

Conrad, R. and Seiler, W.: Influence of temperature, moisture, and organic carbon on the flux of $\mathrm{H}_{2}$ and $\mathrm{CO}$ between soil and atmosphere: Field studies in subtropical regions, J. Geophys. Res., 90(D3), 5699-5709, 1985.

Dansgaard, W.: Stable isotopes in precipitation, Tellus, 16, 436468, 1964.

DeMore, W. B., Sander, S. P., Golden, D. M., Hampson, R. F., Kurylo, M. J., Howard, C. J., Ravishankara, A. R., Kolb, C. E., and Molina, M. J.: Chemical Kinetics and Photochemical Data for Use in Stratospheric Modeling, NASA Jet Propul. Lab., JPL Publication 97-4, pp. 269, Pasadena, Calif., 1997.

Dewey, K. F. and Heim jR., R. R.: Satellite observations of variations in southern hemisphere snow cover, NOAA, Tech. Rep., NESDIS 1, pp. 20, Washington, D.C., 1983.

Duncan, B. N., Martin, R. V., Staudt, A. C., Yevich, R., and Logan, J. A.: Interannual and seasonal variability of biomass burning emissions constrained by satellite observations, J. Geophys. Res., 108(D2), 4100, doi:10.1029/2002JD002378, 2003.

Ehhalt, D. H., Schmidt, U., and Heidt, L. E.: Vertical profiles of molecular hydrogen in the troposphere and stratosphere, J. Geophys. Res., 82(37), 5907-5911, 1977.

FAO Regional Office for Asia and Pacific: Selected Indicators of Food and Agriculture Development in Asia-Pacific Region 1992-2002, Food and Agricultural Organization of the United Nations Regional Office for Asia and Pacific, pp. 207, Bangkok, 2003.

Folland, C. K., Karl, T. R., Christy, J. R., Clarke, R. A., Gruza, G. V., Jouzel, J., Mann, M. E., Oerlemans, J., Salinger, M. J., and Wang, S.-W.: Observed Climate Variability and Change, in Climate Change 2001: The Scientific Basis, Contribution of Working Group I to the Third Assessment Report of the Intergovernmental Panel on Climate Change, edited by: Houghton, J. T., Ding, D. J., Griggs, D. J., Noguer, M., van der Linden, P. J., Dai, X., Maskell, K., and Johnson, C. A., pp. 99-181, Cambridge University press, Cambridge, 2001.

Friedman, I. and Scholz, T. G.: Isotopic composition of atmospheric hydrogen, 1967-1969, J. Geophys. Res., 79(6), 785-788, 1974.

Gerst, S. and Quay, P.: The deuterium content of atmospheric molecular hydrogen: Method and initial measurements, J. Geophys. Res., 105(D21), 26433-26445, 2000.

Gerst, S. and Quay, P.: Deuterium component of the global molecular hydrogen cycle, J. Geophys. Res., 106(D5), 5021-5031, 2001.

Hagemann, R., Nief, G., and Roth, E.: Absolute isotopic scale for deuterium analysis of natural waters. Absolute $\mathrm{D} / \mathrm{H}$ ratio for SMOW, Tellus, 22(6), 712-715, 1970.

Hauglustaine, D. A. and Ehhalt, D. H.: A three-dimensional model of molecular hydrogen in the troposphere, J. Geophys. Res., 107(D17), 4330, doi:10.1029/2001JD001156, 2002.

Heintzenberg, J., Hermann, M., and Theiss, D.: Out of Africa: High aerosol concentrations in the upper troposphere over Africa, Atmos. Chem. Phys., 3, 1191-1198, 2003.

Jacob, D. J., Prather, M. J., Wofsy, S. C., and McElroy, M. B.: Atmospheric distribution of ${ }^{85} \mathrm{Kr}$ simulated with a general circulation model, J. Geophys. Res., 92(D6), 6614-6626, 1987.

Khalil, M. A. K. and Rasmussen, R. A.: Global increase of atmospheric molecular hydrogen, Nature, 347, 743-745, 1990.

Lassey, K. R., Lowe, D. C., and Manning, M. R.: The trend in atmospheric methane $\delta^{13} \mathrm{C}$ and implications for isotopic constraints on the global methane budget, Global Biogeochem. Cycles, 14(1), 41-49, 2000.

Levin, I. and Hesshaimer, V.: Refining of atmospheric transport model entries by the globally observed passive tracer distributions of ${ }^{85}$ krypton and sulfur hexafluoride $\left(\mathrm{SF}_{6}\right)$, J. Geophys. Res., 101(D11), 16745-16755, 1996.

Levitus, S.: Climatological atlas of the world ocean, NOAA, Microfiche, NOAA/ERL GFDL Professional Paper No. 13, pp. 173, Rockville, Md, 1982.

Liebl, K. H. and Seiler, W.: $\mathrm{CO}$ and $\mathrm{H}_{2}$ destruction at the soil surface, in Microbial Production and Utilization of Gases, edited by: Schlegel, H. G., Gottschalk, G., and Pfennig, N., pp. 215-229, E. Goltze K.G., Göttingen, 1976.

Logan, J. A., Prather, M. J., Wofsy, S. C., and McElroy, M. B.: Tropospheric chemistry: A global perspective, J. Geophys. Res., 86(C8), 7210-7254, 1981.

Matthews, E. and Fung, I.: Methane emission from natural wetlands : Global distribution, area, and environmental characteristics of sources, Global Biogeochem. Cycles, 1(1), 61-86, 1987.

Mühle, J., Brenninkmeijer, C. A. M., Rhee, T. S., Slemr, F., Oram, D. E., Penkett, S. A., and Zahn, A.: Biomass burning and fossil fuel signatures in the upper troposphere observed during a CARIBIC flight from Namibia to Germany, Geophys. Res. Lett., 29(19), 1910, doi:10.1029/2002GL015764, 2002.

Nakazawa, T., Miyashita, K., Aoki, S., and Tanaka, M.: Temporal and spatial variations of upper tropospheric and lower stratospheric carbon dioxide, Tellus, B43(2), 106-117, 1991.

Newell, R. E., Browell, E. V., Davis, D. D., and Liu, S. C.: Western Pacific tropospheric ozone and potential vorticity: Implications for Asian pollution, Geophys. Res. Lett., 24(22), 2733-2736, 1997.

Novelli, P. C., Lang, P. M., Masarie, K. A., Hurst, D. F., Myers, R., and Elkins, J. W.: Molecular hydrogen in the troposphere: Global distribution and budget, J. Geophys. Res., 104(D23), 30 427-30 444, 1999.

Ogden, J. M.: Prospects for building a hydrogen energy infrastructure, Annu. Rev. Energ. Environ., 24, 227-279, 1999.

Oliver, J. G. J. and Berdowski, J. J. M.: Global emissions sources and sinks, in: The Climate System, edited by: Berdowski, J. J. M., Guicherit, R., and Heij, B. J., pp. 33-78, A.A. Balkema Publishers/Swets \& Zeitlinger Publishers, Lisse, The Netherlands, 2001.

Prather, M., McElroy, M., Wofsy, S., Russell, G., and Rind, D.: Chemistry of the global troposphere: fluorocarbons as tracers of air motion, J. Geophys. Res., 92(D6), 6579-6613, 1987.

Prather, M. and Spivakovsky, C. M.: Tropospheric OH and the lifetimes of hydrochlorofluorocarbons, J. Geophys. Res., 95(D11), 18 723-18 729, 1990.

Press, W. H., Teukolsky, S. A., Vetterling, W. T., and Flannery, B. P.: Numerical recipes in Fortran 77, 933 pp., Cambridge University 
Press, New York, 1992.

Prinn, R. G., Weiss, R. F., Miller, B. R., Huang, J., Alyea, F. N., Cunnold, D. M., Fraser, P. J., Hartley, D. E., and Simmonds, P. G.: Atmospheric trends and lifetime of $\mathrm{CH}_{3} \mathrm{CCl}_{3}$ and global $\mathrm{OH}$ concentrations, Science, 269, 187-192, 1995.

Rahn, T., Eiler, J. M., Boering, K. A., Wennberg, P. O., McCarthy, M. C., Tyler, S., Schauffler, S., Donnelly, S., and Atlas, E.: Extreme deuterium enrichment in stratospheric hydrogen and the global atmospheric budget of $\mathrm{H}_{2}$, Nature, 424, 918-921, 2003.

Rahn, T., Eiler, J. M., Kitchen, N., Fessenden, J. E., and Randerson, J. T.: Concentration and $\delta \mathrm{D}$ of molecular hydrogen in boreal forests: Ecosystem-scale systematics of atmospheric $\mathrm{H}_{2}$, Geophys. Res. Lett., 29(18), 1888, doi:10.1029/2002GL015118, 2002a.

Rahn, T., Kitchen, N., and Eiler, J.: D/H ratios of atmospheric $\mathrm{H}_{2}$ in urban air: results using new methods for analysis of nano-molar $\mathrm{H}_{2}$ samples, Geochim. Cosmochim. Acta, 66(14), 2475-2481, 2002 b.

Rayleigh, L.: On the distillation of binary mixtures, Philos. Mag., 4(23), 521-537, 1902.

Rhee, T. S., Mak, J., Röckmann, T., and Brenninkmeijer, C. A. M.: Continuous-flow isotope analysis of the deuterium/hydrogen ratio in atmospheric hydrogen, Rapid Commun. Mass Spectrom., 18(3), 299-306, 2004.

Röckmann, T., Rhee, T. S., and Engel, A.: Heavy hydrogen in the stratosphere, Atmos. Chem. Phys., 3, 2015-2023, 2003.

Sander, S. P., Friedl, R. R., Golden, D. M., Kurylo, M. J., Huie, R. E., Orkin, V. L., Moortgat, G. K., Ravishankara, A. R., Kolb, C. E., Molina, M. J., and Finlayson-Pitts, B. J.: Chemical Kinetics and Photochemical Data for Use in Atmospheric Studies, JPL, JPL Publication 02-25, pp. 269, Pasadena, 2003.

Schmidt, U., Kulessa, G., and Roth, E. P.: The atmospheric $\mathrm{H}_{2}$ cycle, in Proceedings of the NATO Advanced Study Institute on Atmospheric Ozone: Its Variation and Human Influences, edited by: Aikin, A. C. and Nicholet, M. pp. 307-322, U.S. Dep. Of Transp., Washington, D.C., 1980.

Schultz, M. G., Diehl, T., Brasseur, G. P., and Zittel, W.: Air pollution and climate-forcing impacts of a global hydrogen economy, Science, 302, 624-627, 2003.

Simmonds, P. G., Derwent, R. G., O’Doherty, S., Ryall, D. B., Steele, L. P., Langenfelds, R. L., Salameh, P., Wang, H. J., Dimmer, C. H., and Hudson, L. E.: Continuous high-frequency observations of hydrogen at the Mace Head baseline atmospheric monitoring station over the 1994-1998 period, J. Geophys. Res., 105(D10), 12 105-12 121, 2000.
Singh, H., Chen, Y., Staudt, A., Jacob, D., Blake, D., Heikes, B., and Snow, J.: Evidence from the Pacific troposphere for large global sources of oxygenated organic compounds, Nature, 410, 1078-1081, 2001

Singh, H. B., Salas, L. J., Chatfield, R. B., Czech, E., Fried, A., Walega, J., Evans, M. J., Field, B. D., Jacob, D. J., Blake, D., Heikes, B., Talbot, R., Sachse, G., Crawford, J. H., Avery, M. A., Sandholm, S., and Fuelberg, H.: Analysis of the atmospheric distribution, sources, and sinks of oxygenated volatile organic chemicals based on measurements over the Pacific during TRACE-P, J. Geophys. Res., 109, D15S07, doi:10.1029/2003JD003883, 2004.

Spivakovsky, C. M., Logan, J. A., Montzka, S. A., Balkanski, Y. J., Foreman-Fowler, M., Jones, D. B. A., Horowitz, L. W., Fusco, A. C., Brenninkmeijer, C. A. M., Prather, M. J., Wofsy, S. C., and McElroy, M. B.: Three-dimensional climatological distribution of tropospheric OH: Update and evaluation, J. Geophys. Res., 105(D7), 8931-8980, 2000.

Talukdar, R. K., Gierczak, T., Goldfarb, L., Rudich, Y., Rao, B. S. M., and Ravishankara, A.R.: Kinetics of hydroxyl radical reactions with isotopically labeled hydrogen, J. Phys. Chem., 100 (8), 3037-3043, 1996.

Tromp, T. K., Shia, R. L., Allen, M., Eiler, J. M., and Yung, Y. L.: Potential environmental impact of a hydrogen economy on the stratosphere, Science, 300, 1740-1742, 2003.

Turner, J. A.: Sustainable hydrogen production, Science, 305, 972 974, 2004.

Warwick, N. J., Bekki, S., Nisbet, E. G., and Pyle, J. A.: Impact of a hydrogen economy on the stratosphere and troposphere studied in a 2-D model, Geophys. Res. Lett., 31(5), L05107, doi:10.1029/2003GL019224, 2004.

Yapp, C. J. and Epstein, S.: Climatic significance of the hydrogen isotope ratios in tree cellulose, Nature, 297, 636-639, 1982.

Yonemura, S., Kawashima, S., and Tsuruta, H.: Carbon monoxide, hydrogen, and methane uptake by soils in a temperate arable field and a forest, J. Geophys. Res., 105(D11), 14 347-14 362, 2000a.

Yonemura, S., Yokozawa, M., Kawashima, S., and Tsuruta, H.: Model analysis of the influence of gas diffusivity in soil on $\mathrm{CO}$ and $\mathrm{H}_{2}$ uptake, Tellus, B52(3), 919-933, 2000b.

Zahn, A., Brenninkmeijer, C. A. M., Asman, W. A. H., Crutzen, P. J., Heinrich, G., Fischer, H., Cuijpers, J. W. M., and van Velthoven, P. F. J.: Budget of $\mathrm{O}_{3}$ and $\mathrm{CO}$ in the upper troposphere : CARIBIC passenger aircraft results 1997-2001, J. Geophys. Res., 107(D17), 4337, doi:10.1029/2001JD001529, 2002. 